\title{
HEAT TRANSFER APPLICATIONS FOR THE STIMULATED RESERVOIR VOLUME
}

\author{
A Thesis \\ by \\ SRIKANTH THORAM
}

\begin{abstract}
Submitted to the Office of Graduate Studies of
Texas A\&M University

in partial fulfillment of the requirements for the degree of

MASTER OF SCIENCE
\end{abstract}

August 2011

Major Subject: Petroleum Engineering 
Heat Transfer Applications for the Stimulated Reservoir Volume Copyright 2011 Srikanth Thoram 


\title{
HEAT TRANSFER APPLICATIONS FOR THE STIMULATED RESERVOIR VOLUME
}

\author{
A Thesis \\ by \\ SRIKANTH THORAM
}

\author{
Submitted to the Office of Graduate Studies of \\ Texas A\&M University \\ in partial fulfillment of the requirements for the degree of \\ MASTER OF SCIENCE
}

\begin{abstract}
Approved by:
Chair of Committee, Christine Ehlig-Economides

Committee Members, Peter Valko

Maria A. Barrufet

Head of Department, Stephen A. Holditch
\end{abstract}

August 2011

Major Subject: Petroleum Engineering 


\begin{abstract}
Heat Transfer Applications for the Stimulated Reservoir Volume. (August 2011)

Srikanth Thoram, B.Tech., Indian School of Mines (Dhanbad)

Chair of Advisory Committee: Dr. Christine Ehlig-Economides
\end{abstract}

Multistage hydraulic fracturing of horizontal wells continues to be a major technological tool in the oil and gas industry. Creation of multiple transverse fractures in shale gas has enabled production from very low permeability. The strategy entails the development of a Stimulated Reservoir Volume (SRV), defined as the volume of reservoir, which is effectively stimulated to increase the well performance. An ideal model for a shale gas SRV is a rectangle of length equal to horizontal well length and width equal to twice the half length of the created hydraulic fractures. This project focused on using the Multistage Transverse Fractured Horizontal Wells (MTFHW) for two novel applications.

The first application considers using the SRV of a shale gas well, after the gas production rate drops below the economic limit, for low grade geothermal heat extraction. Cold water is pumped into the fracture network through one horizontal well drilled at the fracture tips. Heat is transferred to the water through the fracture surface. The hot water is then recovered through a second horizontal well drilled at the other end of the fracture network. The basis of this concept is to use the already created stimulated 
reservoir volume for heat transfer purposes. This technique was applied to the SRV of Haynesville Shale and the results were discussed in light of the economics of the project. For the second application, we considered the use of a similarly created SRV for producing hydrocarbon products from oil shale. Thermal decomposition of kerogen to oil and gas requires heating the oil shale to $700^{\circ} \mathrm{F}$. High quality saturated steam generated using a small scale nuclear plant was used for heating the formation to the necessary temperature.

Analytical and numerical models are developed for modeling heat transfer in a single fracture unit of MTFHW. These models suggest that successful reuse of Haynesville Shale gas production wells for low grade geothermal heat extraction and the project appears feasible both technically and economically. The economics of the project is greatly aided by eliminating well drilling and completion costs. The models also demonstrate the success of using MTFHW array for heating oil shale using SMR technology. 
DEDICATION

To my parents 


\section{ACKNOWLEDGEMENTS}

I would like to thank my committee chair, Dr. Christine Ehlig-Economides, and my committee members, Dr. Peter Valko and Dr. Maria Barrufet, for their guidance and support throughout the course of this research.

Thanks to Computer Modeling Group (CMG) for allowing students to attend their software training classes. Training at CMG made things very easy for me in my research. I would like to thank particularly Mr. K. Patel and Mr. Bob Brugman in CMG for helping me in my research. Thanks also to my friends and colleagues and the department faculty and staff for helping me in some form or the other during my stay at Texas A\&M University. I also want to extend my gratitude to Crisman Institute for funding my research.

Finally, thanks to my father and mother for their faith in me and for allowing me to be as ambitious as I wanted. 


\section{NOMENCLATURE}

b

bpd

C

$\mathrm{c}_{\mathrm{r}}$

$\mathrm{c}_{\mathrm{w}}$

$\mathrm{k}_{\mathrm{r}}$

Q

S

$\mathrm{T}_{\text {in }}$

$\mathrm{T}_{\text {out }}$

$\mathrm{T}_{\mathrm{ri}}$

$\mathrm{T}_{\mathrm{wi}}$

V

$\mathrm{X}_{\mathrm{e}}$

$\mathrm{y}_{\mathrm{f}}$

Greek variables

$\rho$

$\rho_{\mathrm{r}}$

$\rho_{\mathrm{w}}$
Fracture width

Barrels per day

Heat capacity

Specific heat of rock

Specific heat of water

Thermal conductivity of rock

Injection rate per fracture per unit height

Laplace transform variable

Inlet temperature

Outlet temperature

Initial temperature of rock

Initial temperature of water

Velocity

One half of fracture spacing

Fracture length

Density

Density of rock

Density of water 
Dimensionless variables

$\begin{array}{ll}\mathrm{t}_{\mathrm{D}} & \text { Dimensionless time } \\ \mathrm{T}_{\mathrm{rD}} & \text { Dimensionless rock temperature } \\ \mathrm{T}_{\mathrm{wD}} & \text { Dimensionless water outlet temperature } \\ \mathrm{x}_{\mathrm{D}} & \text { Dimensionless fracture spacing } \\ \mathrm{y}_{\mathrm{D}} & \text { Dimensionless fracture length }\end{array}$

\section{Subscripts}

D

Dimensionless

f

Fracture

in

Inlet

out

Outlet

r

Rock

W

Water

Abbreviations

CF

CMG

CRUSH

DOE

DK

EGS

EIA

GETEM
Critical fluids

Computer modeling group

Chevron's technology for the recovery and upgrading of oil from shale

Department of energy

Dual permeability

Enhanced geothermal system

Energy information administration

Geothermal electricity technology evaluation model 


\begin{tabular}{|c|c|}
\hline GEA & Geothermal energy association \\
\hline GFC & Geothermal fuel cell \\
\hline GWP & Global warming potential \\
\hline GWR & Gaver-Wynn-Rho \\
\hline HDR & Hot dry rock \\
\hline ICP & In-situ conversion process \\
\hline LCOE & Levelized cost of electricity \\
\hline LR & Logarithmically refined \\
\hline LS & Logarithmically spaced \\
\hline MINC & Multiple interacting continua \\
\hline MTFHW & Multistage transverse fractured horizontal well \\
\hline MW & Megawatt \\
\hline $\mathrm{nD}$ & Nano Darcy \\
\hline OCA & Organic clay acids \\
\hline ODP & Ozone depletion potential \\
\hline RF & Radio frequency \\
\hline RMA & Regular mud acid \\
\hline SMR & Small modular reactor \\
\hline SRV & Stimulated reservoir volume \\
\hline TOC & Total organic carbon \\
\hline USGS & United States geological survey \\
\hline
\end{tabular}




\section{TABLE OF CONTENTS}

Page

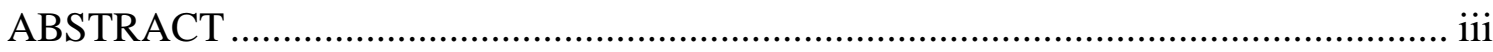

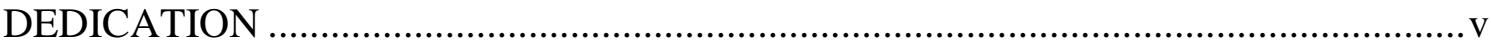

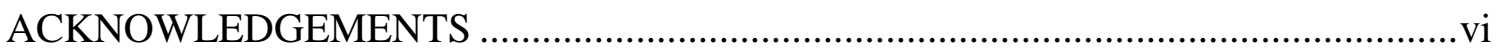

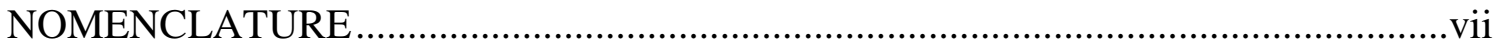

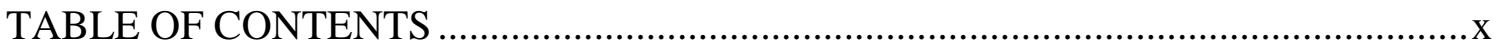

LIST OF FIGURES..................................................................................

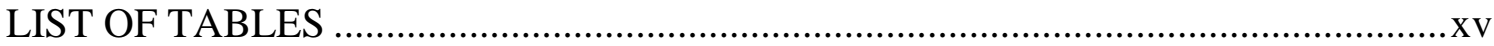

CHAPTER

I INTRODUCTION: BACKGROUND AND LITERATURE REVIEW ..........

1.1 Introduction to HDR geothermal energy development ............................. 1

1.2 Introduction to current oil shale recovery technologies ............................8

1.3 Analytical models for heat transfer in fracture networks ....................... 12

II LOW GRADE GEOTHERMAL HEAT EXTRACTION FROM

HAYNESVILLE SHALE …................................................................. 16

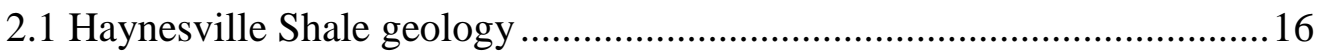

2.2 Description of Haynesville Shale gas well SRV ................................... 18

2.3 Analytical model implementation .....................................................20

2.3.1 Results and discussion..........................................................25

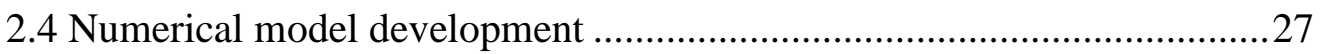

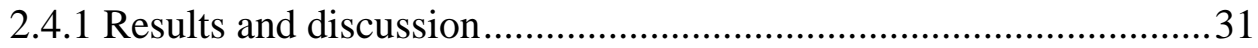

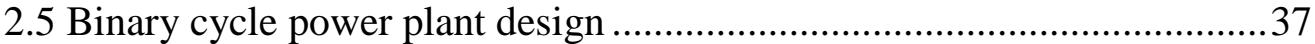

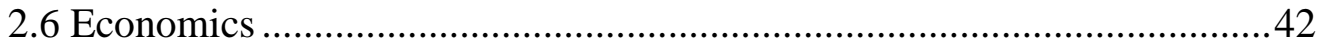

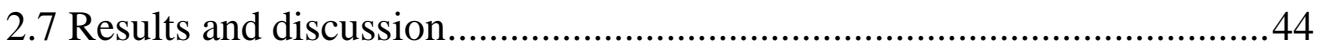

III USING MTFHW FOR HEATING OIL SHALE .....................................46

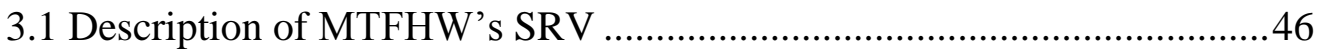

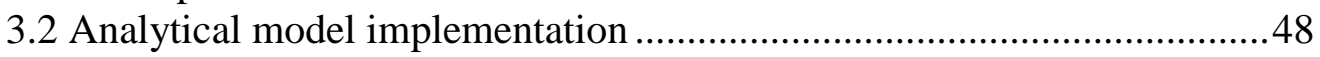

3.2.1 Results and discussion...........................................................51 
CHAPTER Page

3.2.2 Shell's In-situ Conversion Process (ICP) .....................................52

3.3 Numerical model development ..................................................54

3.3.1 Results and discussion...........................................................56

3.4 Using a Small Modular Reactor for generating super-heated steam ........58

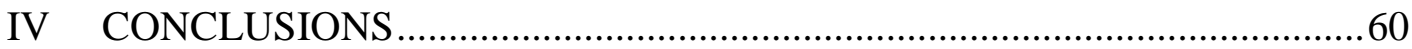

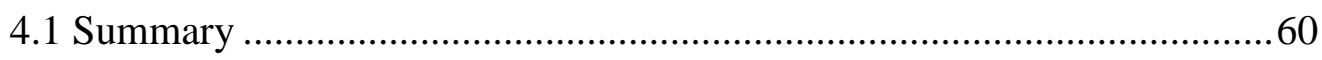

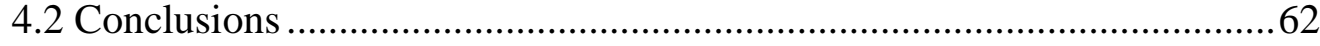

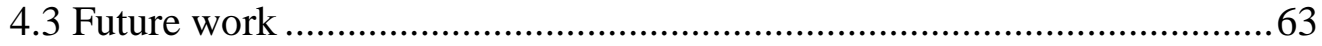

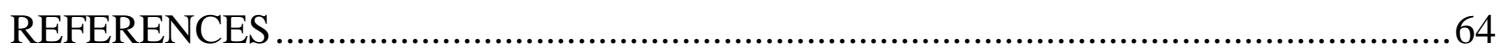

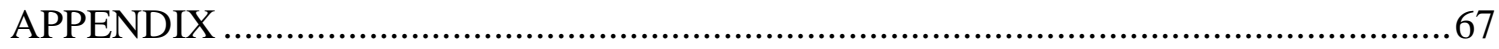

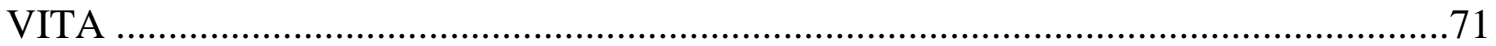




\section{LIST OF FIGURES}

Page

Figure 1: Diagram showing injection-production operational constraints of the geothermal pilot installed at Soultz. Adapted from Cuenot et al. (2008).

Figure 2: Pictorial representation of Phase I and Phase II HDR resource development at Fenton Hill, New Mexico.

Figure 3: Planar view of the SRV. 7

Figure 4: Planar view of the SRV showing the location of virtual no heat flow boundaries for one fracture stage and for one single fracture.

Figure 5: Sample of an oil shale rock showing laminations (Wikipedia).

Figure 6: Typical oil shale retort that is used for heating the crushed oil shale to 550$750^{\circ} \mathrm{F}$ (Wikipedia). 10

Figure 7: Flow chart showing in-situ and the surface processing techniques.

Figure 8: Map showing Haynesville Shale extending over Texas and Louisiana (Adapted from DrillingInfo).

Figure 9: Idealization of Haynesville Shale gas well array.

Figure 10: The above diagram shows the injection-production scheme and the heat extraction volume.

Figure 11: Typical SRV dimensions of Haynesville Shale gas well...........................20

Figure 12: Analytical model for a single fracture unit.

Figure 13: (a) Plot showing water outlet variation with time for different flow rates.

(b) Plot showing power output for case (a).

Figure 14: (a) Plot showing water outlet temperature variation with time for different fracture spacing. (b) Plot showing power output for case (a).

Figure 15: Diagram showing the flow connections in a DK model. Global flow occurs between matrix and fracture cells. In addition there is matrix-fracture flow....28

Figure 16: Diagram showing matrix subgridding in a MINC model. 29 
Figure 17: LS-LR-DK grid design showing matrix and fracture blocks. Adapted from

Rubin (2010). 30

Figure 18: Numerical model for a single fracture unit developed using CMG.

Figure 19: Numerical simulation runs at times $0,10,30$ and 40 years.

Figure 20: Water production rate from the fracture. For a period of 40 years, it can be seen that lower flow rates $(<60 \mathrm{bpd})$ remain constant throughout the injection but values higher tend to drop.

Figure 21: Plot of injector and producer bottom hole pressure (BHP) variation with time.

Figure 22: Plot of enthalpy injection rate variation with time. 36

Figure 23: Plot shows the enthalpy production rate for different injection rates per fracture. Higher is the injection rate, higher is the enthalpy production rate....36

Figure 24: Plot showing higher drop in average temperature for higher flow rates. .......37

Figure 25: Basic binary power plant designed using AspenHYSYS. 38

Figure 26: Dual pressure binary power plant designed using AspenHYSYS. 38

Figure 27: Net power from basic binary and dual pressure binary power plants for different water flow rates.

Figure 28: LCOE values for different energy generation technologies. LCOE value for HDR - Geothermal was estimated to be $\$ 73$ per megawatt hour.

Figure 29: Comparison of water outlet temperature from analytical and numerical models for different per fracture flow rates. Analytical model assumes constant water properties in the fracture, which in reality vary with pressure and temperature.

Figure 30: Idealization of horizontal well array for heating oil shale. The well configuration is similar to one proposed for geothermal heat extraction in Chapter II.

Figure 31: Diagram showing injection and production well pattern for heating oil shale. 
Figure 32: Typical SRV dimensions for heating oil shale. A smaller SRV is chosen

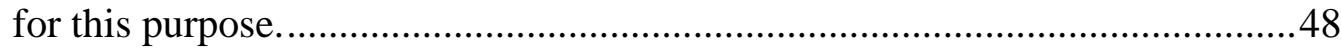

Figure 33: Analytical model for a single fracture unit. .............................................49

Figure 34: Plot showing rock temperature as a function of distance from the fracture after 2 years of continuous heating. .........................................................5 52

Figure 35: The above picture shows the producer and the heater well pattern in ICP

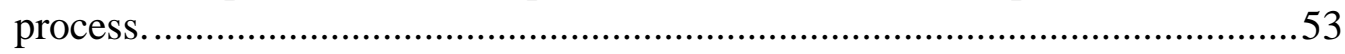

Figure 36: Numerical model for a single fracture unit designed using CMG.................55

Figure 37: Illustration of thermal front propagation in matrix and fracture....................57

Figure 38: SMR for generating super-heated steam.................................................59 


\section{LIST OF TABLES}

Page

Table 1: Analytical model inputs for geothermal heat extraction ................................24

Table 2: Numerical model inputs for geothermal heat extraction................................32

Table 3: AspenHYSYS model inputs............................................................... 40

Table 4: Number of wells required to meet the power plant feed rates. ........................ 40

Table 5: Analytical model inputs for heating oil shale .............................................51

Table 6: Numerical model inputs for heating oil shale. ...........................................56 


\section{CHAPTER I}

\section{INTRODUCTION: BACKGROUND AND LITERATURE REVIEW}

Chapter I introduces the concept of geothermal heat extraction from Hot Dry Rock (HDR) and the role played by Enhanced Geothermal Systems (EGS) in enabling the heat recovery. It also introduces the oil shale resource and currently envisioned recovery technologies. The final section in this chapter introduces the classical analytical models developed for modeling heat extraction from HDR.

\subsection{Introduction to HDR geothermal energy development}

This section gives a brief introduction to HDR geothermal energy development in the United States with particular emphasis given to the possibility of extracting heat from the Haynesville Shale formation. Hydrothermal resources such as hot water and steam have long been used as sources to generate electricity (Mink 2000). Exploitation of a naturally occurring hydrothermal resource is dependent on the availability of substantial amounts of fluid, heat and permeable pathways for the fluids to flow. Hydrothermal reservoirs are relatively rare and their rate of occurrence is low. In contrast, HDR is almost present everywhere in the subsurface and can easily be approached with current drilling technology (Edwards 1982). The majority of the heat in HDR is concentrated in locations of little or no natural permeability to the flow of fluids (Abé et al. 1999).

This thesis follows the style of SPE Journal. 
The EGS strategy is to create a fracture network to provide a flow path through the formation sufficient to mine the heat energy stored in the rock via heat conduction through the rock to the flowing fluid. When injected into the formation cold fluids travel through these high permeability pathways exchanging heat during the course. Hot fluids are then recovered from production wells in hydraulic connection with the created fracture network. Using terminology now common in the petroleum engineering literature, we will term as the Stimulated Reservoir Volume (SRV) that is the rock volume contacted by the created fracture network. EGS is termed "engineered" because the operator has full control over the volume of the stimulated region as demonstrated by HDR reservoirs developed at Soultz (Baria et al. 1999), Rosemanowes (Parker 1999) and Fenton Hill (Duchane 1995).

Cuenot et al. (2008) gives a description of the Soultz EGS project. The objective of this project is to produce electricity from heat stored in fractured crystalline granitic rocks. Vertical boreholes are drilled into the granitic basement intercepting the natural fractures. Calcite, silica and clay scaling on the fracture walls reduce the permeability of the fracture to fluid flow to large extent. The hydraulic connectivity of the boreholes to the fracture networks is increased by periodic hydraulic and/or chemical stimulations. Hydraulic stimulations involve circulating large volumes of water at high flow rates, which causes shearing action across the fracture walls thereby removing the sealing deposits. Chemical stimulations, on the other hand, involve adding chemicals like dilute $\mathrm{HCl}$ to injection water. Some of the other chemicals that can be added to the injection water are Regular Mud Acid (RMA) (to dissolve clays, feldspars and micas), chelatants 
(nitrilotriacetic acid) (to dissolve calcite) and Organic Clay Acids (OCA) (required for high temperature settings with high clay content). Figure 1 shows the geothermal pilot plant that is being operated at Soultz. The project claims to generate roughly $50 \mathrm{MWth}$ power output for production flow rates of 70-100 L/s.

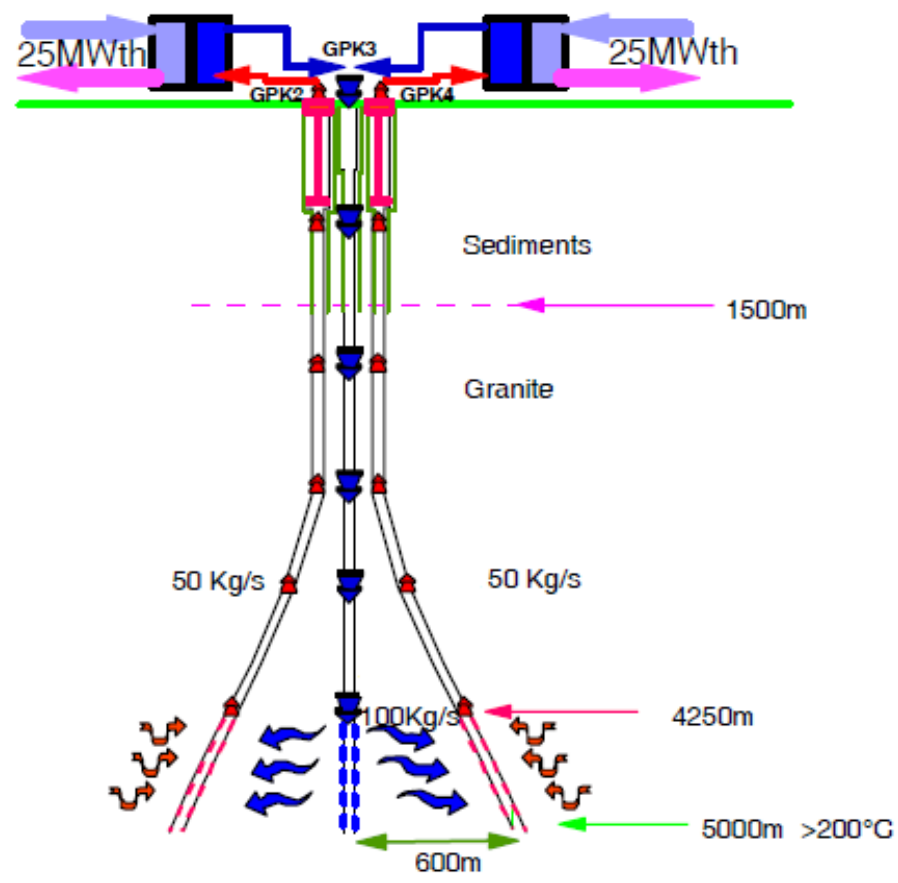

Figure 1: Diagram showing injection-production operational constraints of the geothermal pilot installed at Soultz. Adapted from Cuenot et al. (2008).

Duchane (1996) provides an introduction to HDR geothermal project developed at Fenton Hill in the United States. Fenton Hill was the largest, deepest and the hottest HDR site in the world during 1980 's. The resource has a temperature of $460^{\circ} \mathrm{F}$ at a depth of 11,400 ft. An engineered geothermal reservoir was created by opening the preexisting fractures in the crystalline rock by means of hydraulic stimulation techniques. 
Water is circulated in a closed-loop fashion starting from injector, through fractures and to the producer well as shown in Figure 2. Flow rates of $100-150 \mathrm{gal} / \mathrm{min}$ was achieved with surface water temperatures in excess of $360^{\circ} \mathrm{F}$. Heat energy is extracted from water by passing it through an air-cooled heat exchanger. Cooled water is directed to an injection pump from where it is re-injected back into the borehole.
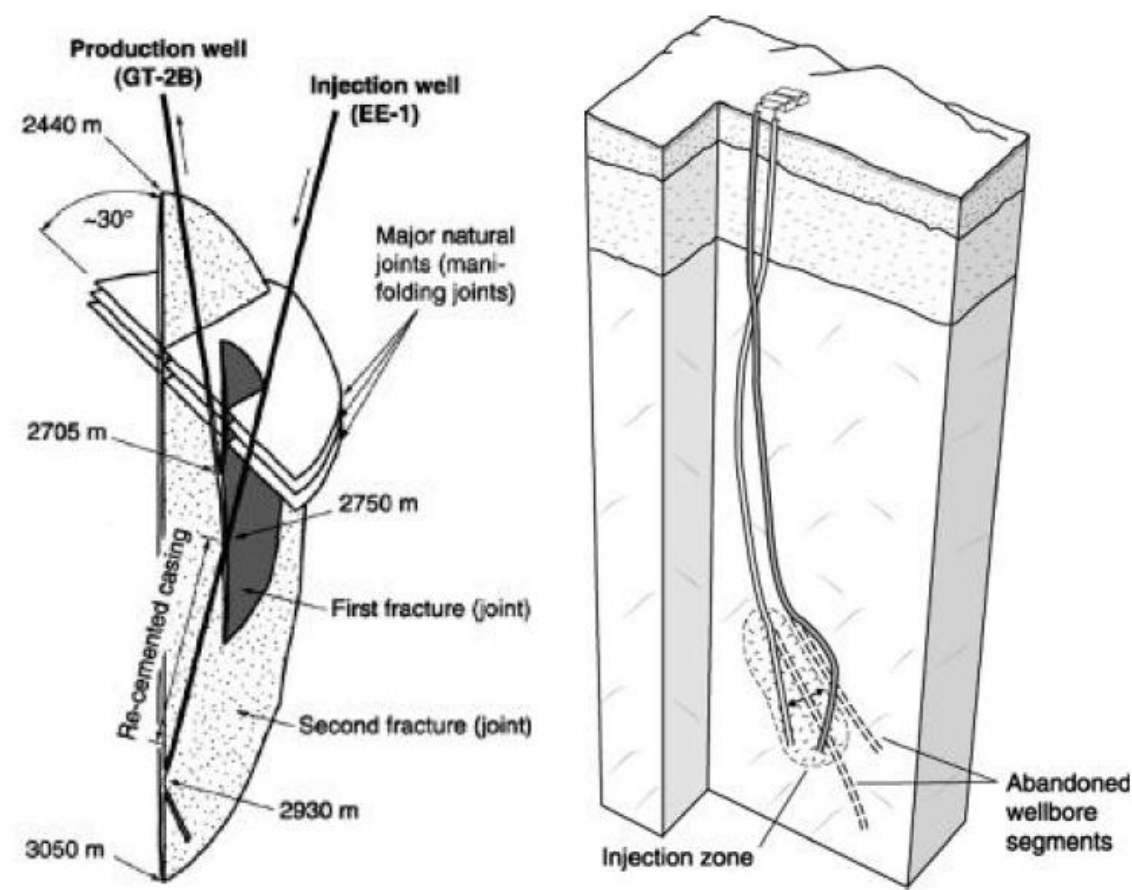

Figure 2: Pictorial representation of Phase I and Phase II HDR resource development at Fenton Hill, New Mexico.

The Future of Geothermal Energy, a project funded by the Department Of Energy (DOE), estimated that EGS alone could reach a capacity of 100,000 megawatt effective (MWe) or more in the United States by 2050, which is roughly one-third of the generating capacity of the coal-fired power plants. According to a survey made by 
United States Geological Survey (USGS), the United States has geothermal resources capable of generating approximately 500,000 MWe of power. This adds up to half of the current total electric power generating capacity from all the energy sources.

EGS offers benefits towards increased power output, siting and sizing flexibility, extended resource life and environmental advantages. The economic viability of a HDR energy resource development using EGS techniques mainly depends on the rate of thermal drawdown. In a practical standpoint, HDR SRV would be sized and operated depending on the capacity of the geothermal power plant at the surface. A small scale commercial geothermal power plant of 5 megawatt (MW) electricity generating capacity operating on water at a temperature of $300^{\circ} \mathrm{F}$ requires a flow rate at least as high as 150 $\mathrm{kg} / \mathrm{s}$. Large HDR systems are required to meet these flow rate requirements. The size of an HDR system can be increased by developing multiple SRVs to serve a single power plant.

The American Oil Shale Corporation and U.S. Atomic Energy Commission, in the year 1971, proposed a method for geothermal heat extraction by circulating water in a closed loop through hot dry locations that were previously fractured using nuclear explosives.

In the recent past, researchers suggested drilling two parallel boreholes adjacent to each other with the second borehole intersecting a series of parallel vertical fractures created as a result of fracturing the formation in the first hole. This technique not only reduces the cost of drilling additional boreholes but also the system designed in such a way can supply energy indefinitely to a power plant of any desired size, but at that time 
directionally drilled wells, and in particular horizontal well drilling technology, were essentially unknown. The past few years witnessed a boom in the application of transverse hydraulic fracturing in horizontal wells as the successful completion technology for shale gas production. With these technical advancements and knowledge base, the operational risks could be brought down and the problems reported earlier in the literature could be solved easily (Abé et al. 1999).

Because of the low thermal conductivity of the rocks, a very large surface area is necessary for heat transfer. The method of multistage transverse fracturing of horizontal wells (MTFHW) can play a significant role in achieving this large surface area for heat transfer. Massive multistage hydraulic fracture treatments are necessary to contact as much rock as possible with a network of fractures that establish adequate connection to the well (Fisher et al. 2004). Two horizontal wells that are in hydraulic connection with each other are used for circulating the fluid. Fluid is injected into one horizontal well and recovered from a second horizontal well. Injected fluid is either cold water or superheated steam depending on the type of application which is either geothermal heat extraction or heating oil shale. MTFHW enables creation of a Stimulated Reservoir Volume (SRV). An ideal model for a shale gas SRV is a rectangle of length equal to the horizontal well length $(\mathrm{L})$ and width equal to twice the half-length $\left(2 \mathrm{x}_{\mathrm{f}}\right)$ of the created hydraulic fractures, as shown in Figure 3. 


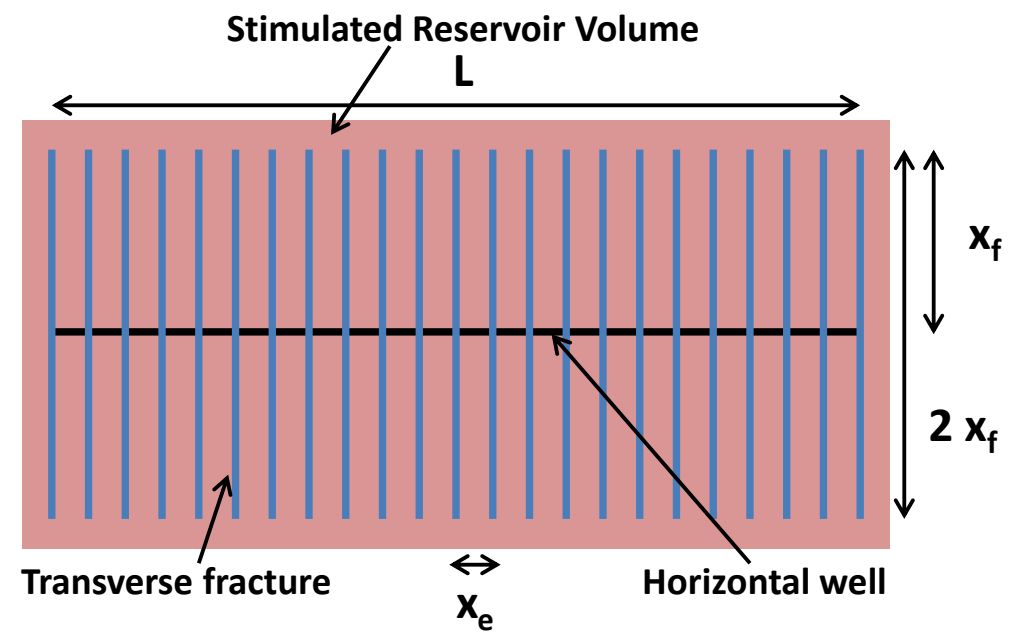

Figure 3: Planar view of the SRV.

Figure 4 shows a diagram of the SRV for a single fracture unit. The temperature interference between two fractures results in the formation of virtual no heat flow boundaries mid-way between the fractures.

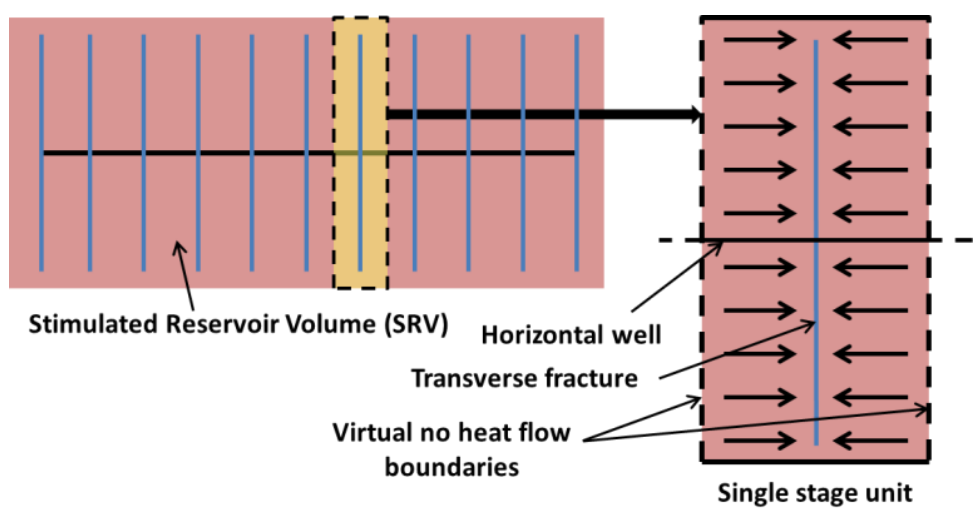

Figure 4: Planar view of the SRV showing the location of virtual no heat flow boundaries for one fracture stage and for one single fracture. 


\subsection{Introduction to current oil shale recovery technologies}

This section describes the oil shale resource play in the United States and existing technologies for oil shale recovery. Oil shale is a laminated sedimentary rock containing immature organic matter called kerogen. Kerogen can be converted to products of commercial value such as oil and gas through the process of heating and hydrogenation. Figure 5 shows a sample of oil shale clearly showing the laminated structure and its dark color characteristic.

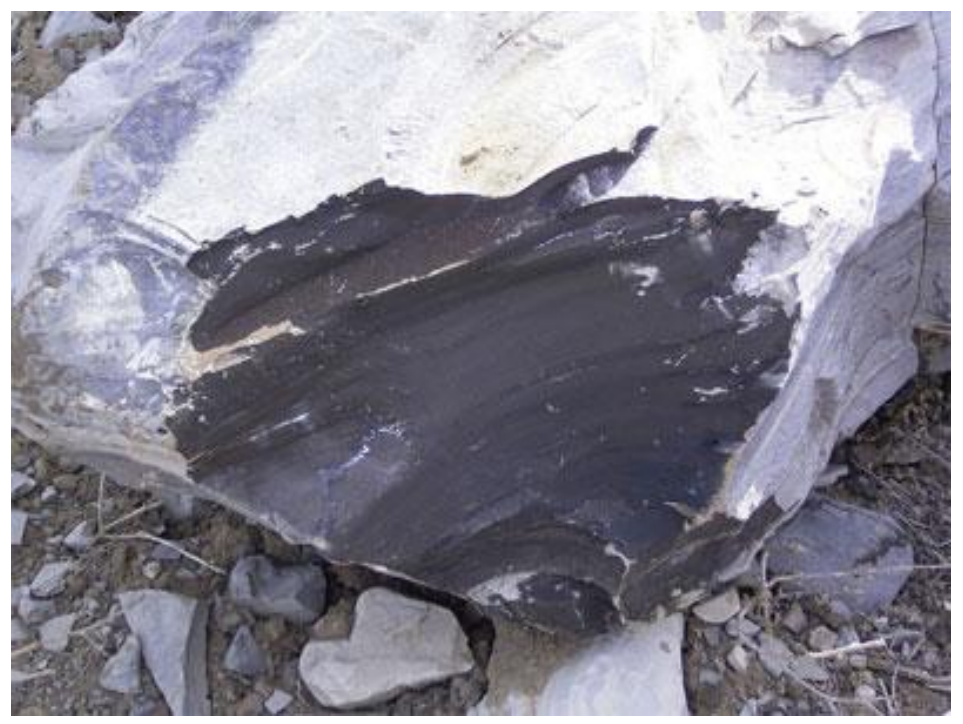

Figure 5: Sample of an oil shale rock showing laminations (Wikipedia).

United States ranks first in terms of total estimated oil shale resource in place.

Out of 6 trillion barrels of the total world resource, about 2 trillion barrels of technically recoverable resource is estimated to be present in the United States. Most of the resource is believed to be concentrated in states of Colorado, Utah and Wyoming. 
Around 1.2 trillion barrels of oil equivalent may be recoverable for a crude oil price in the range 50 to 130 U.S. dollar per barrel of crude (Crawford et al. 2008).

The organic matter present inside oil shale could be of terrestrial, lacustrine or marine origin. The quality and mineral composition of the organic matter primarily depend on its origin. Oil shale deposits generally occur at shallow depths less than 900 meters, where the temperature is not high enough to convert the organic matter to oil and/or gas.

The quality of an oil shale deposit is determined on the basis of its richness/grade (gal/ton), organic material content, hydrogen content, moisture content and concentration on contaminants. The richness is generally determined by a traditional method called Fischer Assay analysis. Any oil shale deposit which yields more than 100 liters of oil per ton of rock by Fischer Assay analysis is said to be a commercially viable resource. A newer method called Rock-Evaluation, still in investigation, may provide a more accurate value of the true potential. For practical considerations, any yield greater than $25 \mathrm{gal} /$ ton is considered an economical and favorable prospect. Advancements in oil shale technology and high market prices can reduce the economic yield. With the crude oil prices remaining above $\$ 80$ per barrel, industry is shifting its attention towards oil shale for the production of secure, domestically sourced transportation fuels.

Two kinds of techniques are currently being considered for oil shale development in the United States - surface processing and in-situ processing (Crawford et al. 2008). In the surface mining process, oil shale is mined (underground or opencast) and crushed at the surface. The crushed material is heated in retorts to a temperature sufficient enough 
to convert the kerogen into hydrocarbon fluids (Whitcombe 1976). Figure 6 shows a typical vertical oil shale retort. The type of mining and heating process, moisture content and the nature of the emissions during processing mainly depend on the type of host rock housing the oil shale deposit. Silica based oil shale deposits tend to have higher moisture content. Carbonate rocks, which crumble on heating, release fines into the generated hydrocarbon fluids, making it difficult for processing. In additional, they release carbon dioxide on heating. The surface footprint involved in these mining processes can be quite large and the process can be environmentally unfriendly.

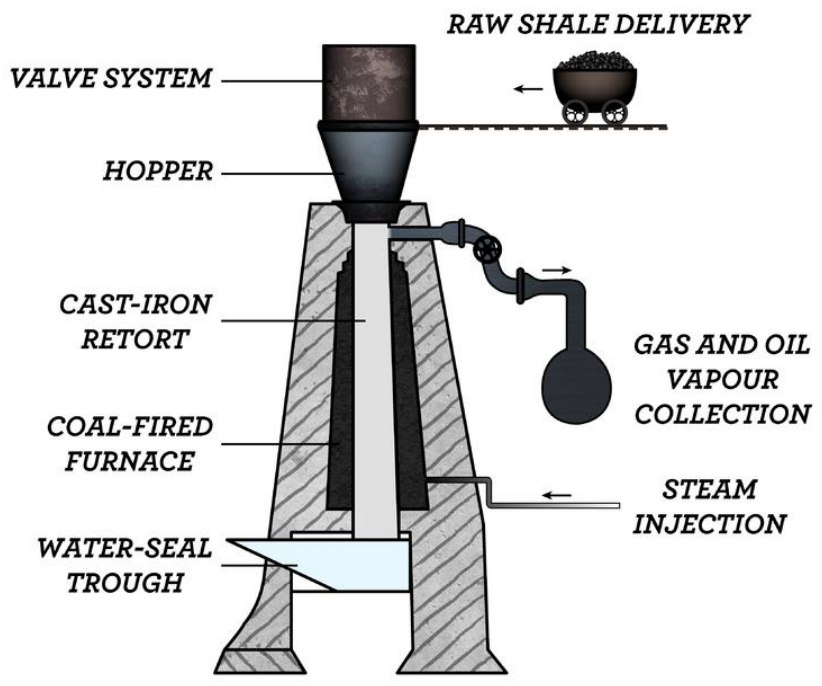

Figure 6: Typical oil shale retort that is used for heating the crushed oil shale to $550-750^{\circ} \mathrm{F}$ (Wikipedia).

Conventional mining techniques fail with deeper and thicker oil shale deposits. In-situ processing involves heating the oil shale in its place and then recovering the generated products using producer wells. Many companies are currently investing capital 
and human resources to bring the oil shale technologies to a commercially attractive state. Methods to heat the resource directly include electric heaters (Shell's ICP), Radio Frequency (RF) with Critical Fluids (CF) technology (Schlumberger's RF/CF technology), super-heated steam (EGL's oil shale process) and Geothermic Fuel Cells (Independent Energy Partners' GFC technology). Other methods have tried to heat the formation by creating a fracture network using hydraulic fracturing techniques and then pumping hot fluids (Chevron's CRUSH) or electrically conductive materials (ExxonMobil's Electrofrac) into the fracture system (Crawford et al. 2008). Figure 7 shows a flow chart comparing the surface and in-situ processing techniques.

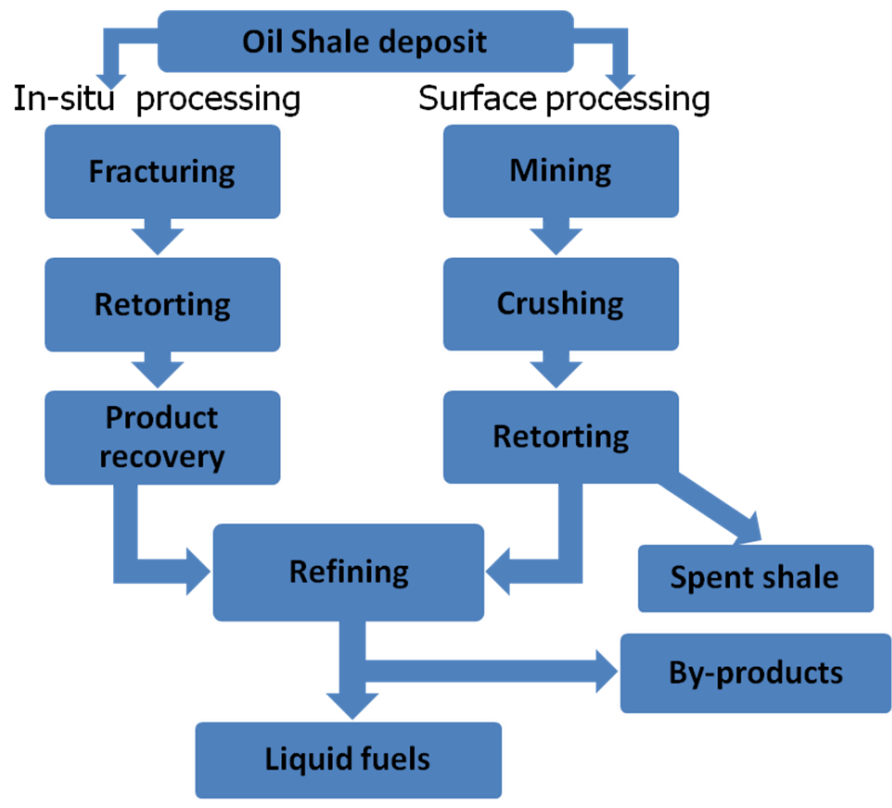

Figure 7: Flow chart showing in-situ and the surface processing techniques. 
The concepts discussed thus far help in better understanding of the existing geothermal heat extraction methods and oil shale heating processes. The next section describes the analytical models developed in the past for modeling heat transfer process in fracture networks.

\subsection{Analytical models for heat transfer in fracture networks}

This section provides describes some of the classical analytical models that were developed for modeling heat transfer in fracture networks. Many researchers (Bödvarsson and Tsang 1982; Gringarten et al. 1975) attempted to accurately model the process of heat extraction from fractured HDR in the past using analytical models for a series of uniformly spaced parallel vertical fractures of uniform aperture. These models enable a clear understanding of the dependence of electrical power output on injection/production constraints and SRV dimensions.

Bodvarsson (1969) and Gringarten et al. (1975) assumed that created fractures are separated by impermeable blocks having homogeneous and isotropic properties. Gringarten et al. (1975) reported two important conclusions in his work. Dividing the flow rate among different identical fractures results in a reduced flow rate per fracture and hence the water outlet temperature would drop at a lower rate. Reducing the fracture spacing will result in a faster temperature drop, but the amount of energy recovered from the rock will be higher. Bodvarsson (1969) developed a similar modeling technique but with the assumption of no thermal interaction between the fractures (large fracture 
spacing). From their work, it can be concluded that the determination of fracture spacing and injection rate is critical to the HDR system development.

A well-defined injection/production scheme for fractured geothermal reservoirs is essential in order to avert the detrimental effects on power output due to premature breakthrough of cold water in the production wells (Bödvarsson and Tsang 1982). Various researchers (Bodvarsson 1969; Gringarten et al. 1975) studied this problem for the case of an injection well completely penetrating a series of identical horizontal fractures. The cold water front advances rapidly during early times of injection with little or no heat transfer taking place into the rock matrix. The rate of heat transfer increases in the rock matrix and that in the fracture decreases until both the rates become equal. This is the point where the cold thermal front in the rock matrix reaches the no heat flow boundaries. A uniform energy sweeping mechanism will exist in the system from this point of time.

Pruess and Bodvarsson (1984) studied the thermal effects of injection into fractured reservoirs by identifying the fastest breakthrough paths using tracer tests, pressure transient testing and numerical models developed for non-isothermal injection tests. From their experiments, they concluded that the tracer and the pressure transient tests alone are inadequate to study the phenomena of thermal breakthrough. A semi analytical model, developed for 3D heat flow in injection-production systems in vertical fractures, concludes that shutting-in an injection well responsible for thermal interference along a preferential flow path will avoid large drops in outlet water temperature. 
Harlow and Pracht (1972) discussed other mechanisms for cooling the rock. Thermal contraction of the rock results in the creation of new cracks, creating pathways for the water to reach the untouched perimeter of the hot rock. The power output is enhanced with increase in convection heat transfer between water and hot rock (apart from conduction), preferential crack penetration towards hotter zones in the reservoir, greater hot rock volume available for heat transfer and increase in fracture width due to rock contraction. One major concern can be loss of water during circulation due to unexpected fracture growth, making it difficult to maintain pressure at the desired level for injection of cold water.

Bodvarsson (1974) considered a more general inter granular fluid flow model by assigning a finite value to the permeability of the rock matrix. Heat transfer between the rock matrix and the fracture can take place by convection in addition to conduction. In this study, we focus mainly on heat transfer and restrict the flow to created fractures in an impermeable rock matrix.

The above introduction gives a general understanding of the HDR geothermal energy exploitation and currently existing oil shale recovery technologies in the United States. In this report, we use both analytical and numerical models to evaluate heat transfer potential either from the formation to the flowing fluid, as for EGS application, or from the working fluid to the formation in the oil shale application. After a brief geological description of Haynesville Shale, Chapter II gives results of a case study based on the Haynesville shale indicating that using existing shale gas wells for the EGS application appears to be a feasible and potentially economically competitive approach 
for electric power generation. The chapter also shows a binary cycle power plant designed using the AspenHYSYS program, and concludes by evaluating the economics of the geothermal heat extraction using the Geothermal Electricity Technology Evaluation Tool (GETEM). Chapter III investigates using the SRV created by MTFHW for heating oil shale using a small modular nuclear reactor for generator super-heated steam. The final chapter provides summary and conclusions. 


\section{CHAPTER II}

\section{LOW GRADE GEOTHERMAL HEAT EXTRACTION FROM HAYNESVILLE SHALE}

The chapter begins with an introduction to Haynesville Shale geology and its unique characteristics that justify its potential as a geothermal energy resource. Typical dimensions of a Haynesville Shale gas well SRV are also presented in this section. The analytical and numerical models are applied to this particular SRV and the results are analyzed. A binary cycle power plant was designed using the Aspen HYSYS program. The chapter concludes by modeling the project economics using the GETEM tool.

\subsection{Haynesville Shale geology}

The Haynesville Shale is a black organic-rich shale of Upper Jurassic age located in Northwest Louisiana and Northeast Texas, as shown in Figure 8. It extends over an area of 5.8 million acres. It is overlain by Bossier Shale and underlain by the Cotton Valley Limestone in Texas and the Smackover carbonate formation in Louisiana. The gross thickness varies from $150-350 \mathrm{ft}$. Porosity varies from $5-12 \%$ and the shale exhibits low water saturation values ranging between 25-35\%. Average Total Organic Content (TOC) of the shale is less than $4 \%$ indicating high thermal maturity (Wang and Liu 2011). Based on core measurements, Pope et al. (2010) estimated the matrix permeability to range between 5-800 nano-Darcys (nD). 


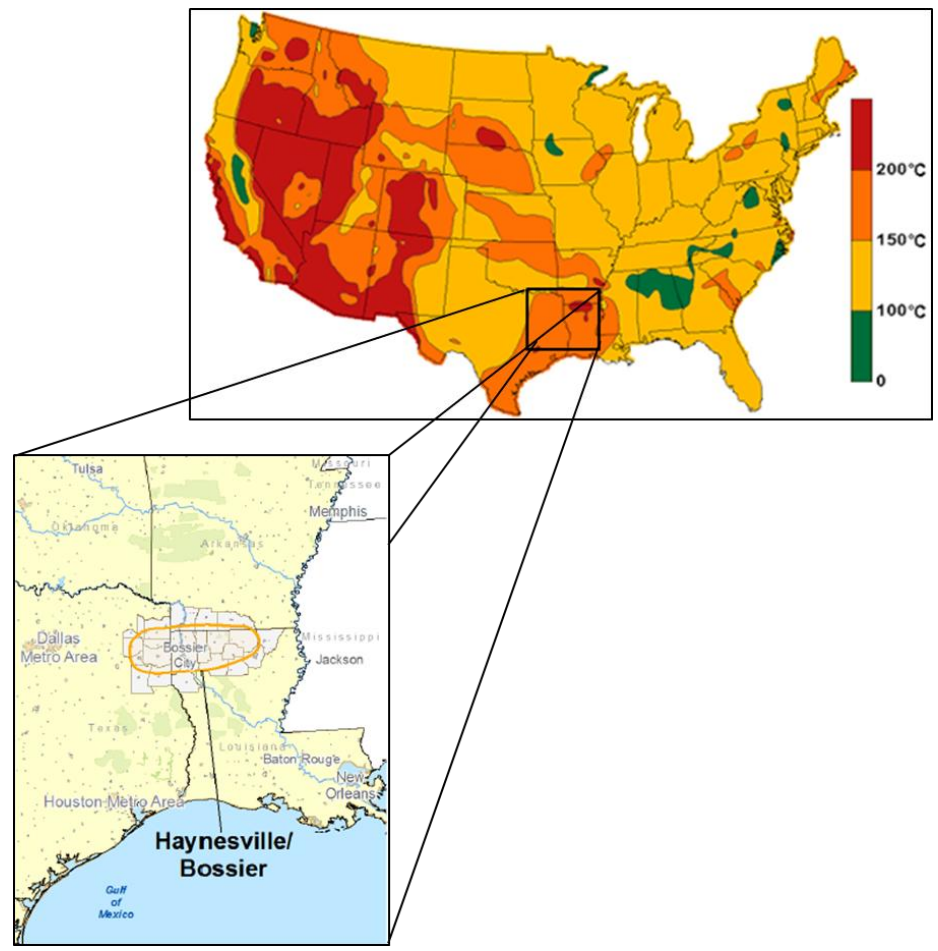

Figure 8: Map showing Haynesville Shale extending over Texas and Louisiana (Adapted from DrillingInfo).

The Haynesville Shale is different from other shale plays because it occurs at a relatively greater depth (11000-14500 ft), it is tremendously high pressured (0.7-0.9 $\mathrm{psi} / \mathrm{ft}$ ) and exhibits formation temperatures above $300^{\circ} \mathrm{F}$ (Thompson et al. 2010). The total technically recoverable gas content of the Haynesville Shale is estimated to be 251 TCF with $80 \%$ existing as free gas and the remaining $20 \%$ adsorbed on organic surfaces (Fisher et al. 2004).

According to reports published by U.S. Energy Information Administration (EIA) in March 2011, the natural gas production from the Haynesville Shale in Louisiana has surpassed production from the Barnett Shale in Texas, making it one of 
the largest and the most active shale gas play in the whole United States. EIA reports current natural gas production from the Haynesville Shale at 5.5 BCF/D. The objective of this study is to use existing shale gas wells after the gas production falls below the economic rate for geothermal heat extraction. At temperatures in excess of $300^{\circ} \mathrm{F}$, the Haynesville Shale formation can double as a low grade geothermal resource.

\subsection{Description of Haynesville Shale gas well SRV}

Figure 9 shows a diagram representing the approximate configuration of Haynesville shale gas wells. The wells are about $4000 \mathrm{ft}$ long and spaced $600 \mathrm{ft}$ apart. Created fracture half lengths are about $300 \mathrm{ft}$, and the spacing between fractures is about $50 \mathrm{ft}$. Typically there are 5 to 6 fractures per stage, and 10 to 12 stages per well. In Figure 9, red lines represent fractures created from horizontal wells represented by blue lines. It is essential to obtain good connectivity between the wells through the fracture network. Fluid injection may itself be sufficient to achieve the required connectivity. While we do not provide any specific basis for the above statements, we note that operators offer frequent anecdotal evidence about inter-well connectivity. A key element in the success of this project is the use of already existing wells for injection and production of the working fluid for geothermal heat extraction. 


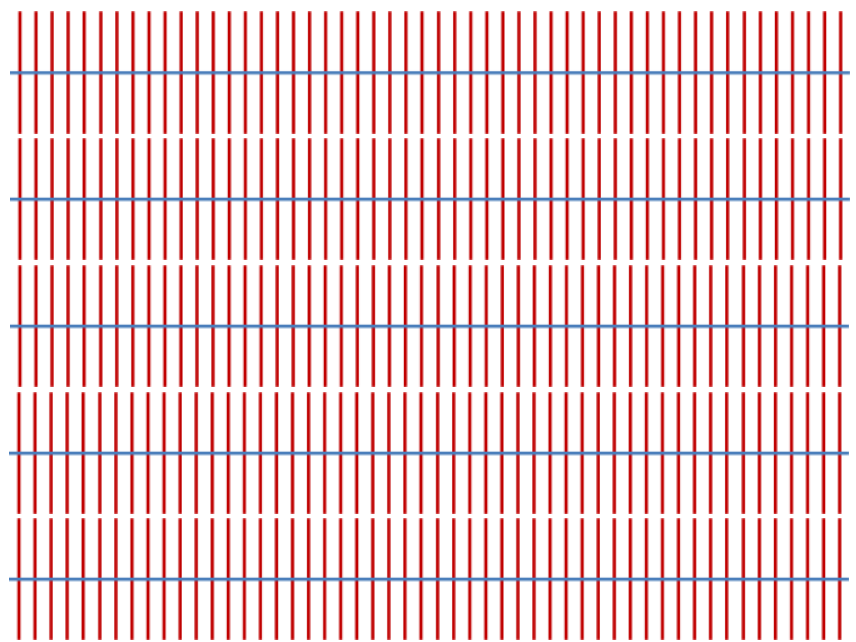

Figure 9: Idealization of Haynesville Shale gas well array.

Figure 10 shows the injection and production well configuration for geothermal heat extraction from Haynesville Shale. Typical dimensions for the SRV of a MTFHW shale gas well in Haynesville formation are shown in Figure 11.

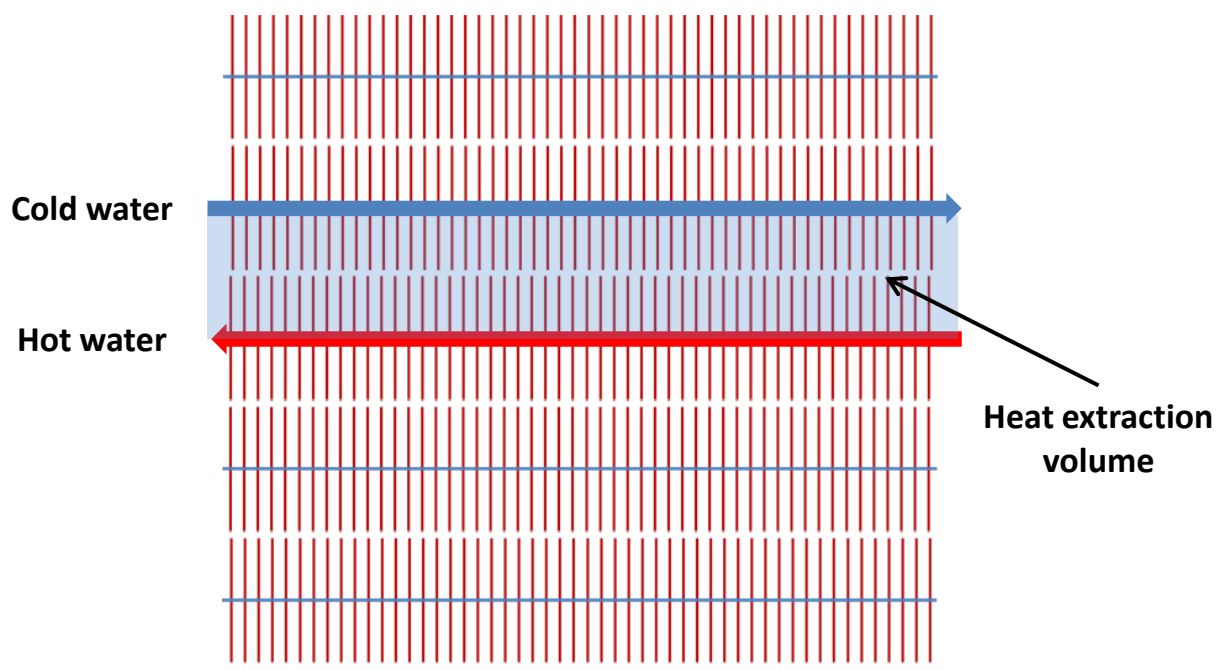

Figure 10: The above diagram shows the injection-production scheme and the heat extraction volume. 


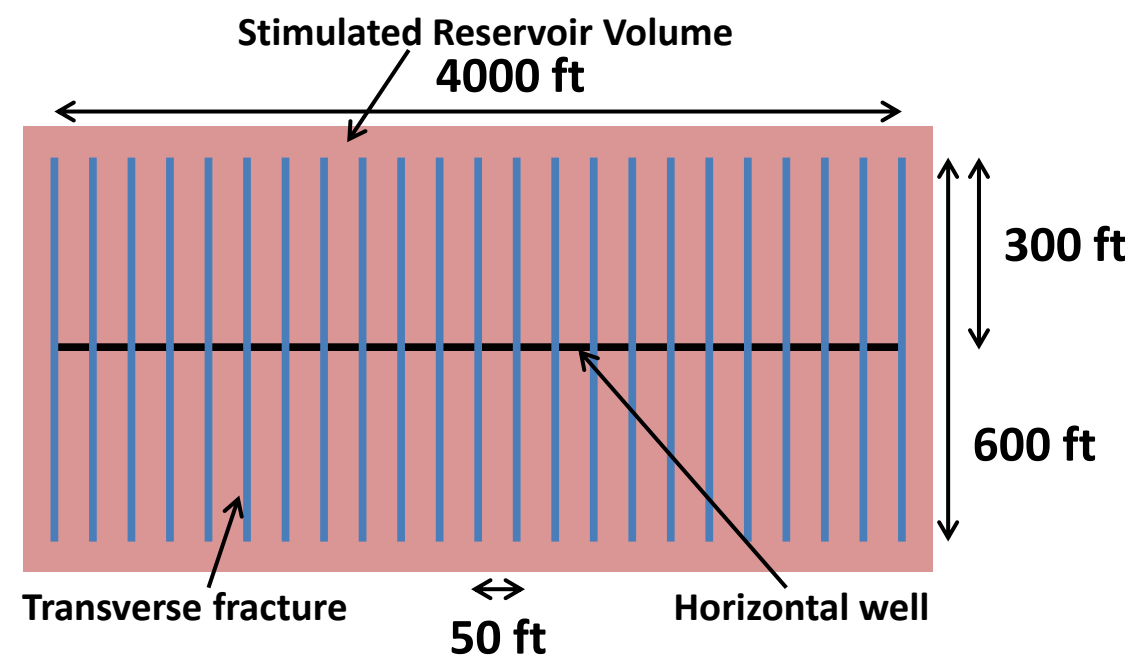

Figure 11: Typical SRV dimensions of Haynesville Shale gas well.

\subsection{Analytical model implementation}

This section describes the analytical model used for modeling heat extraction.

We used the analytical model developed for a series of parallel equally spaced transverse fractures of uniform width by Gringarten et al. (1975). Figure 12 shows a picture of the analytical model. We assume that the fractures are separated by impermeable blocks having homogeneous and isotropic properties. A rectilinear coordinate system was set in such a way that the $\mathrm{x}$-axis is perpendicular to the fractures and the $\mathrm{y}$-axis passes midway between the matrix blocks. Using the symmetry element, only one fracture is modeled. The plane of the fracture is oriented along the z-axis. Because the heat flow to adjacent fractures will interfere, insulated heat flow boundaries were assumed located at a distance of ' $x_{\mathrm{e}}$ ' in either direction. 


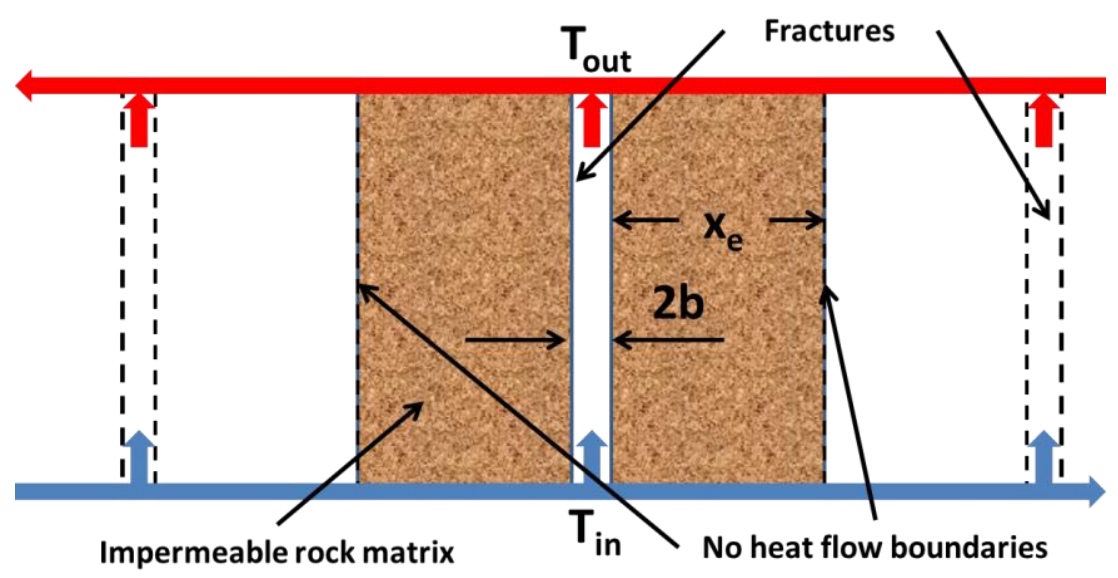

Figure 12: Analytical model for a single fracture unit.

Cold water at a temperature ' $\mathrm{T}_{\mathrm{wi}}$ ' was injected at $\mathrm{y}=0$ into the fracture. The initial rock temperature was ' $\mathrm{T}_{\mathrm{ri}}$ ' and its thermal conductivity ' $\mathrm{k}_{\mathrm{r}}$ ' was assumed constant. Mass and volumetric flow rate of the injected water were assumed constant. The product of the density ( $\rho$ ) and heat capacity (C) for both rock and water was assumed constant. We assume that the heat transfer takes place only through conduction in the horizontal direction parallel to the $\mathrm{x}$-axis and through conduction and convection along the $\mathrm{y}$-axis in the fracture. The water temperature was assumed to be uniform in any cross-section limited to the width of the fracture and is equal to the temperature of the rock at $\mathrm{x}=\mathrm{b}$ for all times. The geothermal gradient was neglected in this model. Differential equations governing this particular heat transfer problem are given by Gringarten et al. (1975). 
$b \rho_{w} c_{w}\left[\frac{\partial T_{w}(y, t)}{\partial t}+v \frac{\partial T_{w}(y, t)}{\partial y}\right]=k_{r} \frac{\partial T_{r}(x, y, t)}{\partial x}($ at $x=b)$

$\frac{\partial^{2} T_{r}(x, y, t)}{\partial x^{2}}=\frac{\rho_{r} c_{r}}{k_{r}} \frac{\partial T_{r}(x, y, t)}{\partial t}$

where,

$v$, velocity;

$\rho_{w}$, density of water;

$c_{w}$, specific heat of water;

$\rho_{r}$, density of rock;

$c_{r}$, specific heat of rock;

Equation (1) accounts for conduction and convection in water and Equation (2) accounts for conduction in the rock. The rock and the water temperatures should satisfy the following boundary conditions.

$$
\begin{aligned}
& T_{r}(x, y, t)=T_{w}(y, t)=T_{r i}, t<\frac{y}{v} \\
& T_{r}(x, 0, t)=T_{w}(0, t)=T_{r i}, t<0 \\
& T_{r}(x, 0, t)=T_{w}(0, t)=T_{w i}, t \geq 0 \\
& T_{w}(y, t)=T_{r}(b, y, t), \forall y, t \\
& \frac{\partial T_{r}(x, y, t)}{\partial x}\left(\text { at } x=x_{e}\right)=0
\end{aligned}
$$

Laplace transforms of Equations (1) and (2) were solved simultaneously subject to conditions (3)-(7). The solution for the water outlet temperature in Laplace space is given by Equation (8) (Gringarten et al. 1975) using dimensionless variables defined according to equations (9) to (12). Equation (8) was inverted numerically using the 
Gaver-Wynn-Rho (GWR) algorithm written in Mathematica. The Mathematica code is provided in the Appendix. The program generates the water outlet temperature from a single fracture unit as a function of time. Table 1 gives the details of inputs for the analytical model.

$T_{w D}\left(y_{D}, s\right)=\frac{1}{s} \operatorname{Exp}\left[-y_{D} s^{\frac{1}{2}} \tanh \left(\frac{Q \rho_{w} c_{w} x_{e}}{2 k_{r} y_{f}}\right) s^{\frac{1}{2}}\right]$

where,

$y_{f}$, fracture length;

$s$, laplace transform variable;

$Q$, injection rate per fracture per unit fracture height;

with the following dimensionless variables:

$y_{D}=\frac{y}{y_{f}}$

$x_{D}=\frac{x}{b}$

$t_{D}=\frac{\rho_{w}{ }^{2} c_{w}{ }^{2} Q^{2} t}{4 k_{r} \rho_{r} c_{r} y_{f}^{2}}$

$T_{r D}\left(x_{D}, y_{D}, t_{D}\right)=\frac{T_{r i}-T_{r}(x, y, t)}{T_{r i}-T_{w i}}$

where,

$y_{D}$, dimensionless fracture length;

$x_{D}$, dimensionless fracture spacing;

$t_{D}$, dimensionless time;

$T_{r D}$, dimensionless rock temperature; 
Table 1: Analytical model inputs for geothermal heat extraction.

\begin{tabular}{|c|c|c|}
\hline \multicolumn{3}{|c|}{ Reservoir properties } \\
\hline $\mathrm{T}_{\mathrm{ri}},{ }^{\circ} \mathrm{F}$ & Initial temperature & 350 \\
\hline $\mathrm{k}_{\mathrm{r}}, \mathrm{Btu} / \mathrm{ft}-\mathrm{day}-{ }^{\circ} \mathrm{F}$ & Thermal conductivity & 24.36 \\
\hline$\rho_{\mathrm{r}}, \mathrm{lb} / \mathrm{ft}^{3}$ & Density & 144 \\
\hline $\mathrm{c}_{\mathrm{r}}, \mathrm{Btu} / \mathrm{lb}-{ }^{\circ} \mathrm{F}$ & Specific heat & 0.391 \\
\hline \multicolumn{3}{|c|}{ Injection fluid properties (Water) } \\
\hline $\mathrm{T}_{\text {wi }},{ }^{\circ} \mathrm{F}$ & Temperature & 86 \\
\hline$\rho_{\mathrm{w}}, \mathrm{lb} / \mathrm{ft}^{3}$ & Density & 62.4 \\
\hline $\mathrm{c}_{\mathrm{w}}, \mathrm{Btu} / \mathrm{lb}-{ }^{\circ} \mathrm{F}$ & Specific heat & 1 \\
\hline \multicolumn{3}{|c|}{ Well and stimulated fracture properties } \\
\hline $\mathrm{L}, \mathrm{ft}$ & Well length & 4000 \\
\hline $\mathrm{y}_{\mathrm{f}}, \mathrm{ft}$ & Fracture half-length & 300 \\
\hline $2 x_{e}, f t$ & Fracture spacing & 50 \\
\hline $\mathrm{h}, \mathrm{ft}$ & Fracture height & 100 \\
\hline nof, - & No. of fractures & 80 \\
\hline
\end{tabular}

The above described analytical model is a simple heat transfer problem with temperature as the only variable. Incorporating pressure into the model puts limit on several operational variables. The model mainly does not account for pressure losses in the fracture. The next section introduces the features of Dual Permeability (DK) and Multiple INteracting Continua (MINC) models and their incapability to completely model heat transfer in a single fracture unit. It is followed by description of a new numerical modeling technique that has the features of both DK and MINC models. The model was originally developed by CMG to model gas flow in shale fracture networks. A similar numerical model is used for modeling heat transfer in a single fracture unit. 


\subsubsection{Results and discussion}

This section applies the previously described analytical model for the Haynesville shale case. From sensitivity studies at different injection rates we observe that the water outlet temperature drop is slower for smaller flow rates and faster for larger flow rates. Cold thermal front breakthrough in the production well at higher flow rates results in larger water outlet temperature drop and is detrimental to the performance of the power plant installed at the surface. For an operation period of 40 years, per fracture rates of 30-50 bpd provide constant power output at the surface. Figure 13 (a) shows the variation of water outlet temperature with time for different injection rates per fracture.

A single fracture can be considered as a unit energy source, and because heat transfer from outside the SRV is neglected due to low thermal conductivity of the rocks, the total energy for the well is given by the number of created fractures. The economics depend partly on how fast we want to extract heat from this energy unit. Figure 13 (b) shows plot of power output versus time for the case shown in Figure 13 (a). We see that higher power is obtained for higher per fracture rates, but this exhausts the resource sooner. We also see that the power output is nearly constant over time for per fracture rates lying between 30-50 bpd. In these studies, for a fixed well length the fracture spacing (and hence the number of fractures) is varied in order to obtain uniform power output that is optimal for efficient power plant operation. While optimal fracture spacing can be found with this approach, if existing wells are used, the existing fracture spacing will be the only choice. 


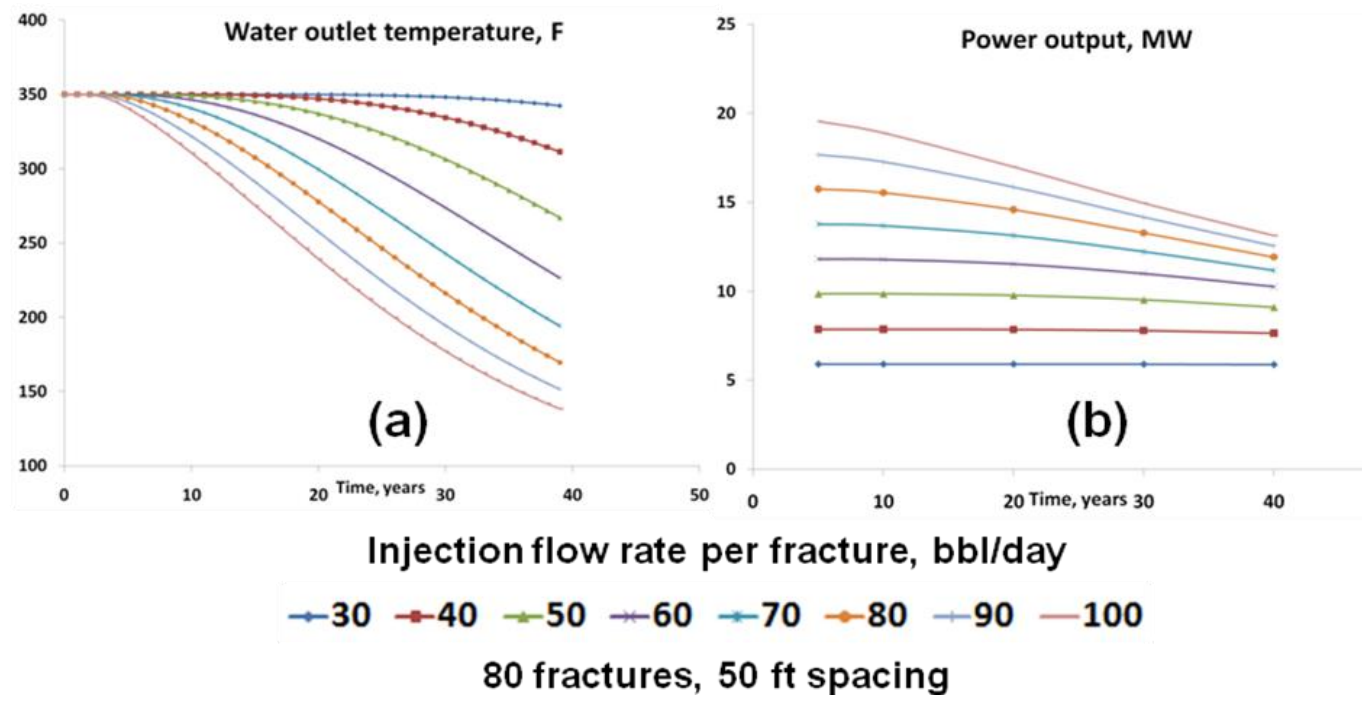

Figure 13: (a) Plot showing water outlet variation with time for different flow rates. (b) Plot showing power output for case (a).

Figure 14 (a) shows the dependence of water outlet temperature on the number of fractures. We observe that increasing the number of fractures increases the rate of drop in water outlet temperature and hence results in more power output as seen in Figure 14 (b). 


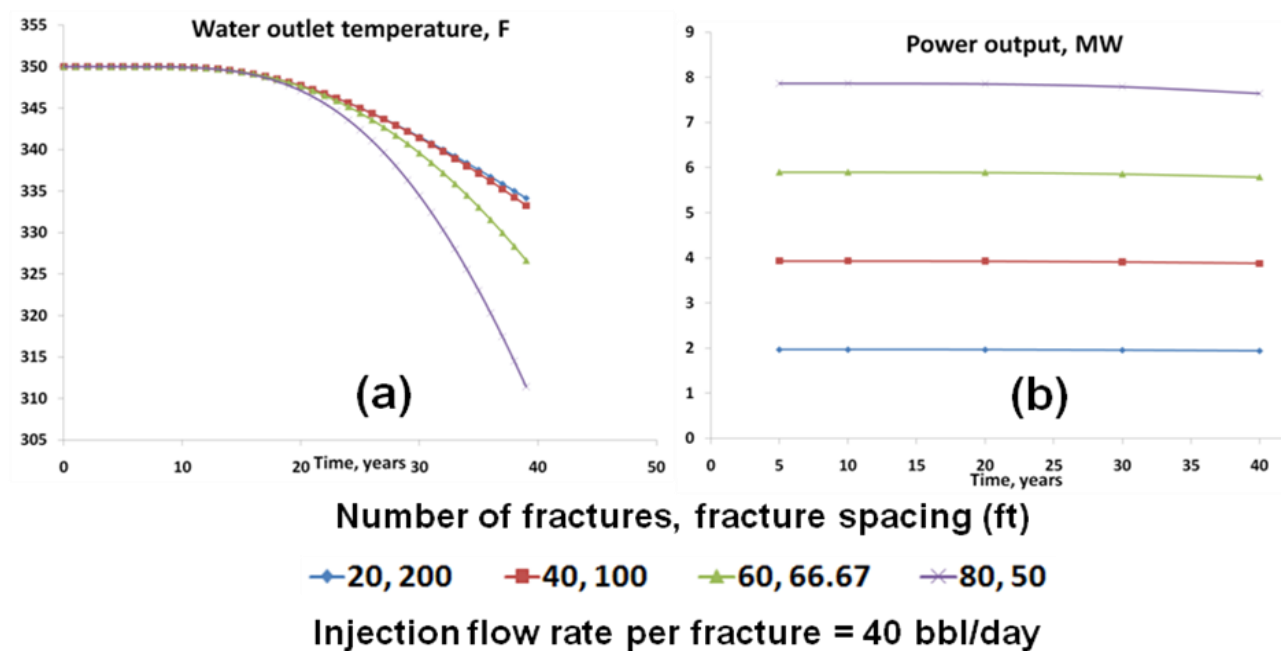

Figure 14: (a) Plot showing water outlet temperature variation with time for different fracture spacing. (b) Plot showing power output for case (a).

\subsection{Numerical model development}

This section begins with an introduction to classical numerical modeling techniques and their drawbacks followed by a description of the Computer Modeling Group (CMG) numerical model used for this study. In a standard Dual Permeability (DK) model, matrix is represented by one cell and the fracture is represented by one cell. Flow can occur between matrix-matrix, matrix-fracture and fracture-fracture as shown in Figure 15. 


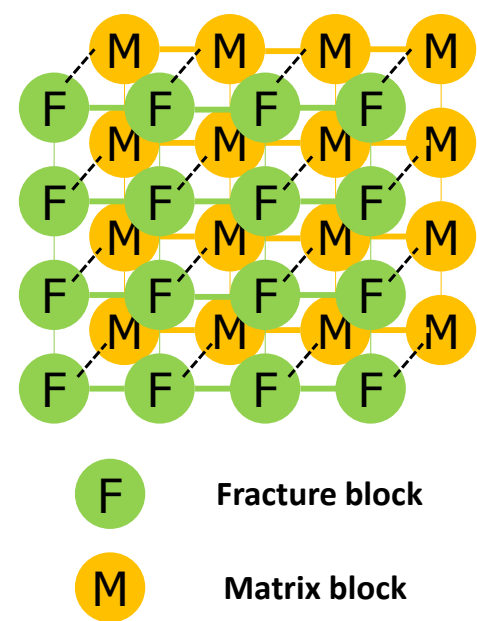

Figure 15: Diagram showing the flow connections in a DK model. Global flow occurs between matrix and fracture cells. In addition there is matrix-fracture flow.

MINC is an approximate method for modeling fluid and heat flow in fractured porous media. The method is applicable when there is fluid and heat exchange between fractures and unfractured rock. MINC models differ from conventional dual porosity models in the nature of matrix-fracture fluid exchange. They can model the interporosity flow at the matrix-fracture contact in a transient way. In this method, the matrix blocks are discretized into a series of nested matrix cells, as shown in Figure 16. Each set of nested matrix cells has a fracture cell associated with it. Only the outermost cell can communicate with the fracture cell. The spacing between each nested cell increases logarithmically away from the fracture in order to capture the transient effects of fluid and heat flow at the matrix-fracture contact. Nested matrix cells can communicate with each other. Unlike MINC grid cells, MINC fracture network block can communicate with fractures in adjacent MINC fracture network blocks (Rubin 2010). 


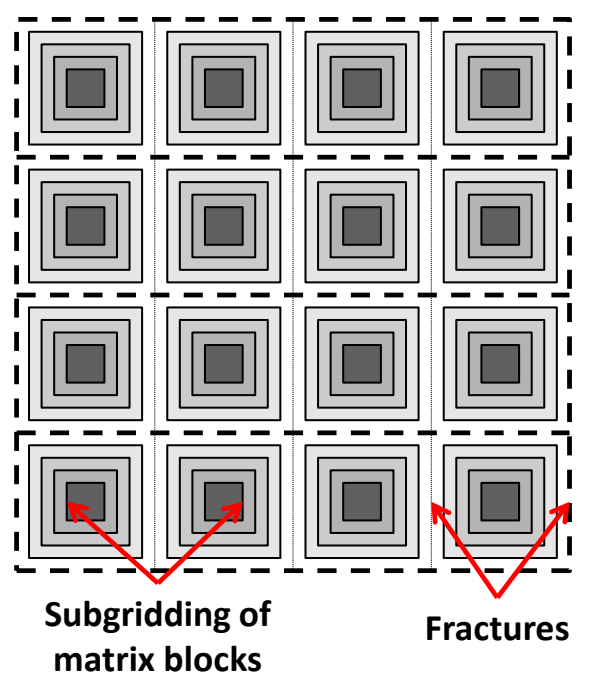

Figure 16: Diagram showing matrix subgridding in a MINC model.

DK and MINC models cannot completely model fluid and heat flow in low permeability fractured shales. MINC models are better to some extent because they can capture the transient effects of heat flow (Rubin 2010). Our CMG model incorporates features of both DK and MINC in such a way so as to overcome their limitations. Figure 17 shows Log Spaced-Log Refined-Dual Permeability (LS-LR-DK) grid modeling technique developed by $\mathrm{CMG}$. 


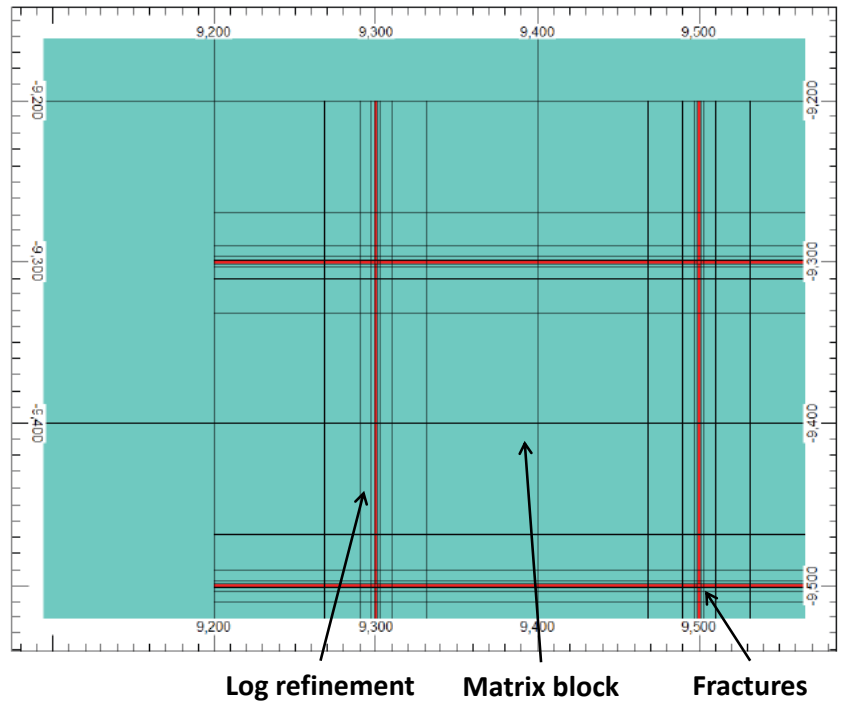

Figure 17: LS-LR-DK grid design showing matrix and fracture blocks. Adapted from Rubin (2010).

Our numerical model for the single fracture unit of SRV uses the CMG STARS module for thermal simulation. The model is patterned after that of Rubin (2010). However, instead of using correction factors to adjust grid block temperatures, and because heat transfer depends on the width of the fracture, the propped fracture is modeled at its true width. A dual permeability model was used even though there is no flow taking place between the rock matrix and the fracture because the matrix permeability is effectively zero. The logarithmic refinement incorporated into the numerical model was used to capture the thermal front movement in the fracture and the rock matrix. Figure 18 shows the grid used in the simulation. 


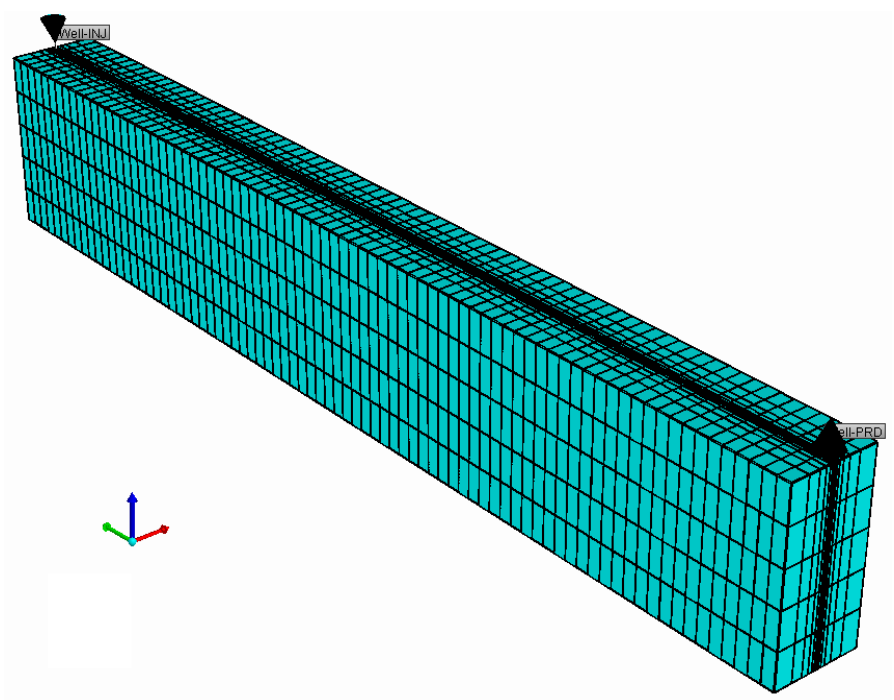

Figure 18: Numerical model for a single fracture unit developed using CMG.

\subsubsection{Results and discussion}

This section applies the previously described numerical model for the Haynesville Shale case. The analytical model has its advantages in that it can be used for a quick estimate of power output and is very effective in studying the effect of injection rate and number of fractures on the power output. By incorporating pressure along with temperature, the numerical simulation model gives a more realistic view of the heat extraction problem. Simulations for various injection rates starting from $30 \mathrm{bpd}$ to 100 bpd provided new insights. Table 2 gives the details of the inputs used for the numerical model. Since the formation is assumed to be impermeable, there is no flow taking place between matrix and the fracture. All the water injected into the fracture is produced as hot water. 
Table 2: Numerical model inputs for geothermal heat extraction.

\begin{tabular}{|c|c|}
\hline \multicolumn{2}{|l|}{ Reservoir properties } \\
\hline Initial temperature, ${ }^{\circ} \mathrm{F}$ & 350 \\
\hline Reservoir pressure, psia & 9000 \\
\hline Depth, ft & 12000 \\
\hline Thermal conductivity, Btu/ft-day-F & 24.36 \\
\hline Heat capacity, Btu/ $/ \mathrm{ft}^{3}-\mathrm{F}$ & 56.06 \\
\hline Matrix porosity, fraction & 0.05 \\
\hline Matrix permeability, md & 1E-09 \\
\hline Fracture porosity (natural fracture), fraction & $2 \mathrm{E}-05$ \\
\hline Fracture permeability (natural fracture), md & $2 \mathrm{E}-05$ \\
\hline Rock compressibility, $1 / \mathrm{psi}$ & $1 \mathrm{E}-06$ \\
\hline $\begin{array}{c}\text { Initial water saturation } \\
\text { (matrix and propped fracture) }\end{array}$ & 0.8 \\
\hline \multicolumn{2}{|l|}{ Fluid properties } \\
\hline Thermal conductivity of water, Btu/ft-day-F & 8.6 \\
\hline Injection water temperature, ${ }^{\circ} \mathrm{F}$ & 86 \\
\hline \multicolumn{2}{|c|}{ Simulation model description } \\
\hline Grid model & LS-LR-DK grid \\
\hline Fracture model & Infinite conductivity \\
\hline Grid & $1 * 20 * 5$ \\
\hline Grid block dimensions & $50 \mathrm{ft} * 30 \mathrm{ft} * 20 \mathrm{ft}$ \\
\hline $\begin{array}{c}\text { Local grid refinement } \\
\text { (log refinement in } x \text {-direction) }\end{array}$ & $15 * 4 * 1$ \\
\hline SRV dimensions & $50 \mathrm{ft} * 600 \mathrm{ft} * 100 \mathrm{ft}$ \\
\hline Simulation run time, years & 40 \\
\hline
\end{tabular}

Numerical simulation results at four different times 0 years, 10 years, 20 years and 40 years are shown in Figure 19. The progression of the cold thermal front from injector to producer is clearly visible in this figure. 

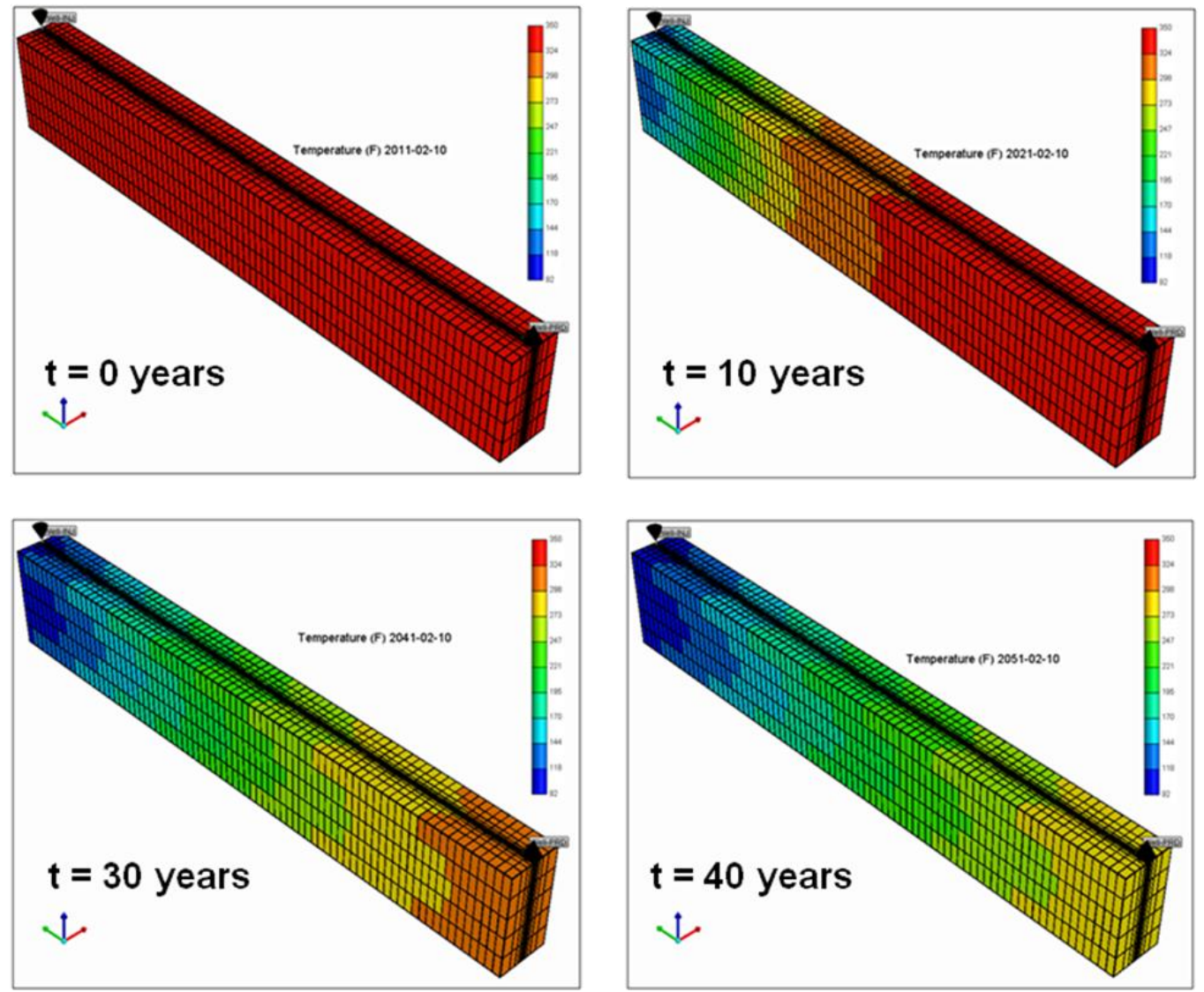

Figure 19: Numerical simulation runs at times $0,10,30$ and 40 years.

Figure 20 shows plot of water rate variation with time. Since there is no fluid exchange between matrix and the fracture, injection and the production rates are equal. Figure 21 shows plot of injector and producer bottom hole pressure as a function of time. The pressure gradient in the fracture is adjusted by changing the injector bottom hole pressure. Water is produced at constant bottom hole pressure from the producer. Pressure drop in the fracture increases with increasing flow rate. Hence in order to flow at higher rates, the bottom hole pressure needs to be lowered further. From Figure 20, we can conclude that for a bottom-hole pressure of $10,000 \mathrm{psi}$, per fracture flow rates of 30 
bpd, 40 bpd and 50 bpd are maintained constant in the fracture throughout the plant operation period.

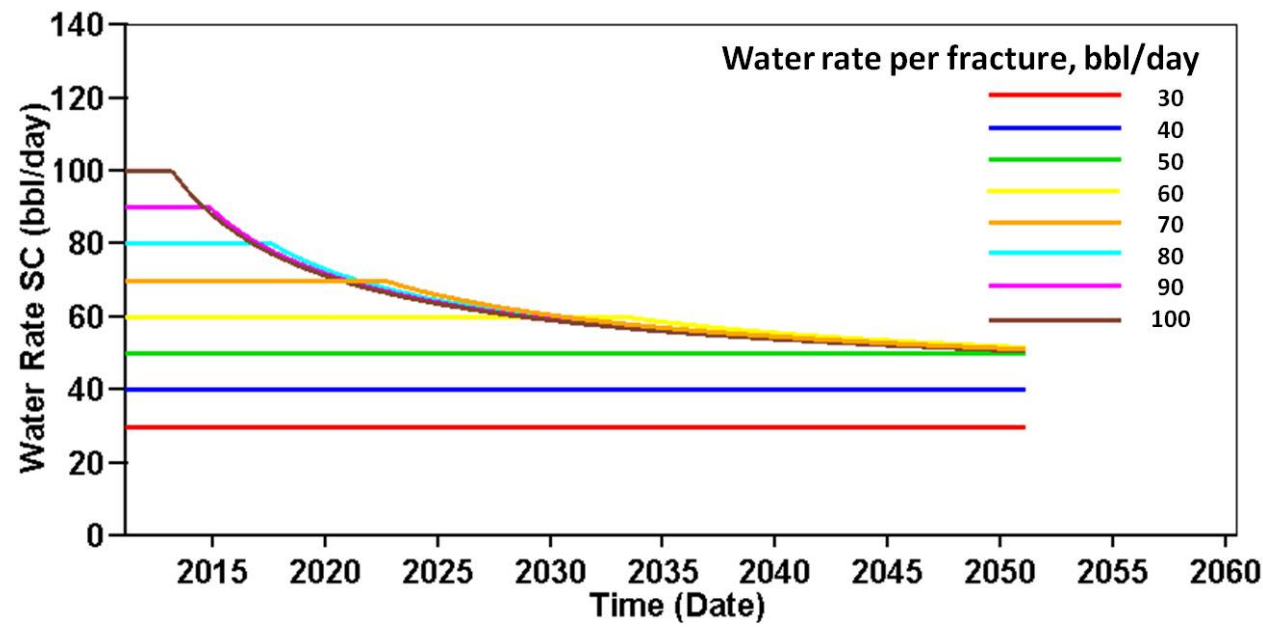

Figure 20: Water production rate from the fracture. For a period of 40 years, it can be seen that lower flow rates $(<60$ bpd) remain constant throughout the injection but values higher tend to drop.

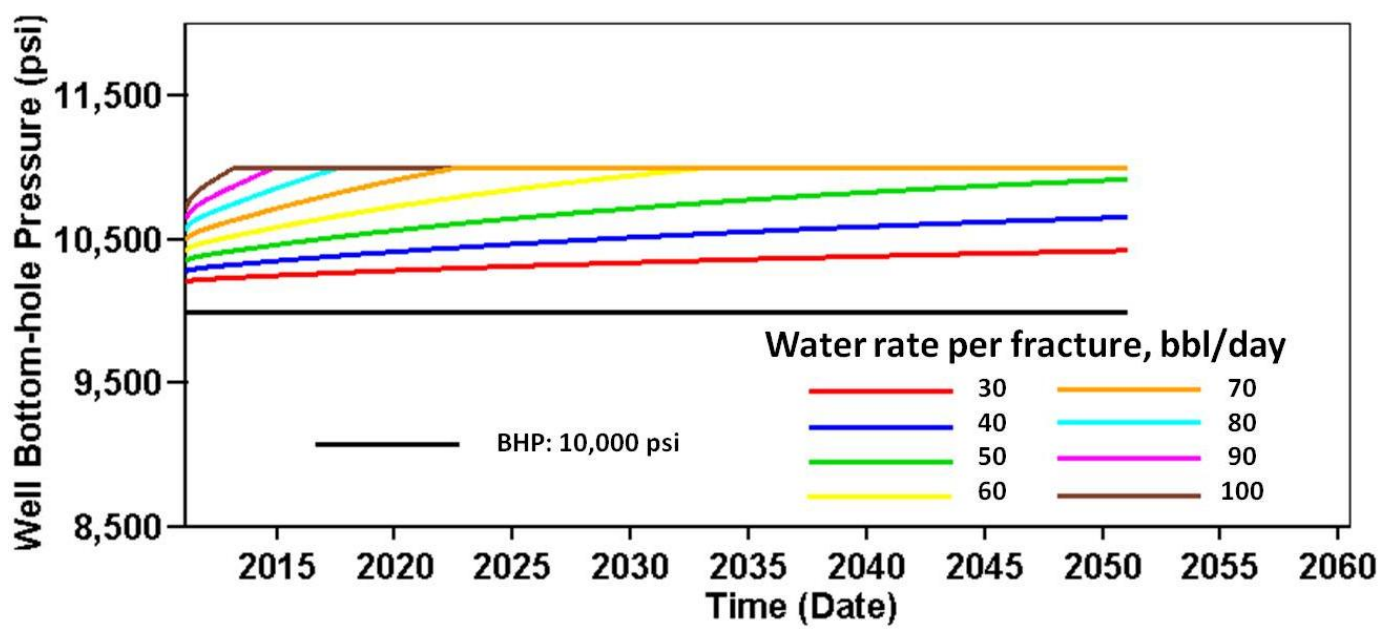

Figure 21: Plot of injector and producer bottom hole pressure (BHP) variation with time. 
Lowering the bottom hole pressure beyond a certain limit will turn out be uneconomical if one is planning to re-inject the produced water, after it has been extracted of its heat content, back into the formation. Re-injection, in this case, results in higher compression costs. From the results of analytical and numerical models, we conclude that it is more economical to produce at lower rates and at high bottom hole pressures even if it results in lower power output. Adopting such a strategy will increase the life of the prospect. Moreover, producing the hot water as pressurized liquid by means of down-hole pumps has its advantages - it is easier to handle single phase flow than a multiphase flow and also the pressure losses are less in a single phase flow. Steam and non-condensable gases are formed when the fluid goes below the flash point and it could result in severe calcite scaling problems in reservoir, pipelines, valves, surface equipment etc. A pump is required to make sure the fluid always stays above the flash point. The pump setting depth in a production well is selected based on the nature of the reservoir and fluid properties. Drop in fluid temperature below a certain point can also lead to silica scaling in pre-heaters pipelines, heat exchangers and in injection wells downstream of the power plant (Knaus et al. 2010).

Figure 22 shows plot of injection enthalpy rate variation with time. Figure 23 shows plot of enthalpy production rate variation with time. We observe that the rate of enthalpy drawdown from the fracture unit increases with increasing per fracture flow rate. Figure 24 shows plot of average temperature variation with time for a fracture unit. We observe that increasing the injection rate increases the drop in the average temperature. 


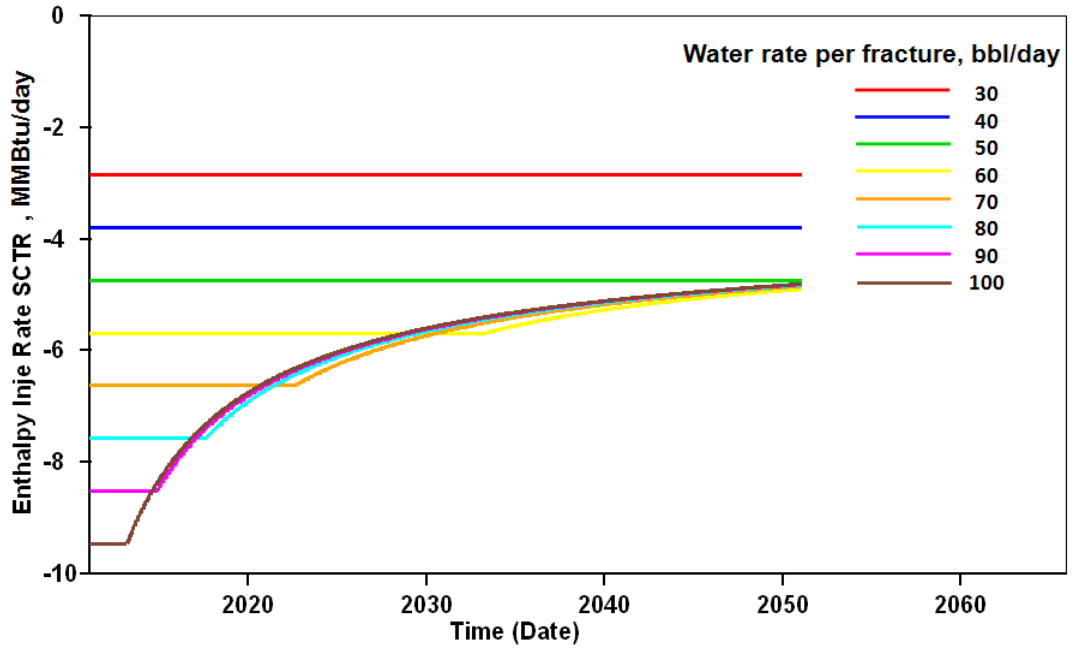

Figure 22: Plot of enthalpy injection rate variation with time.

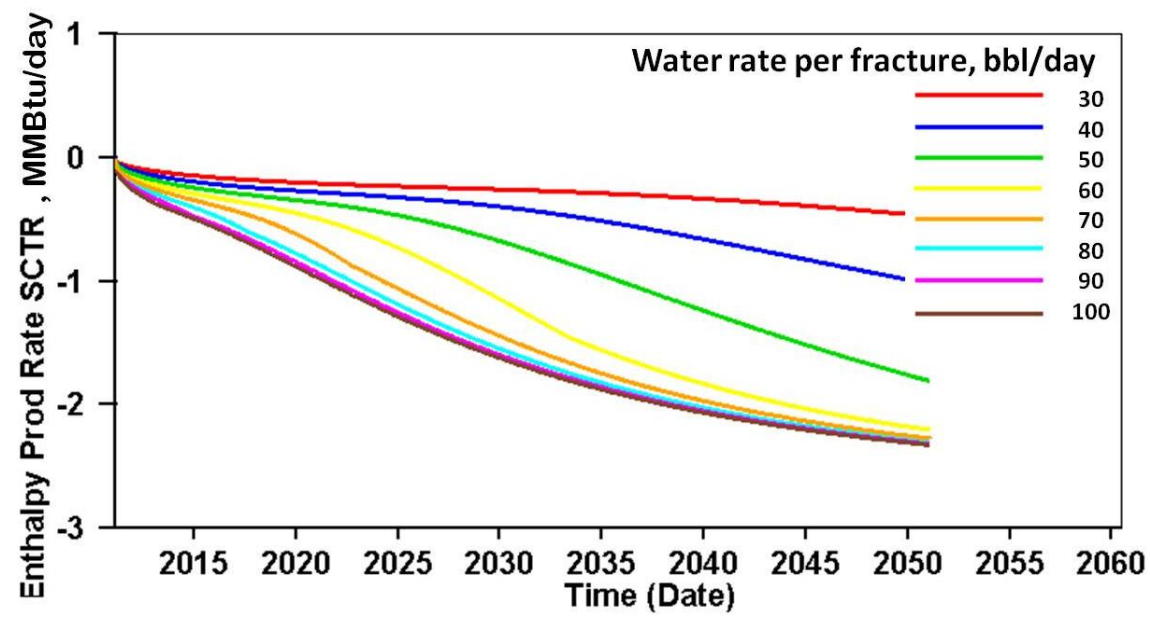

Figure 23: Plot shows the enthalpy production rate for different injection rates per fracture. Higher is the injection rate, higher is the enthalpy production rate. 


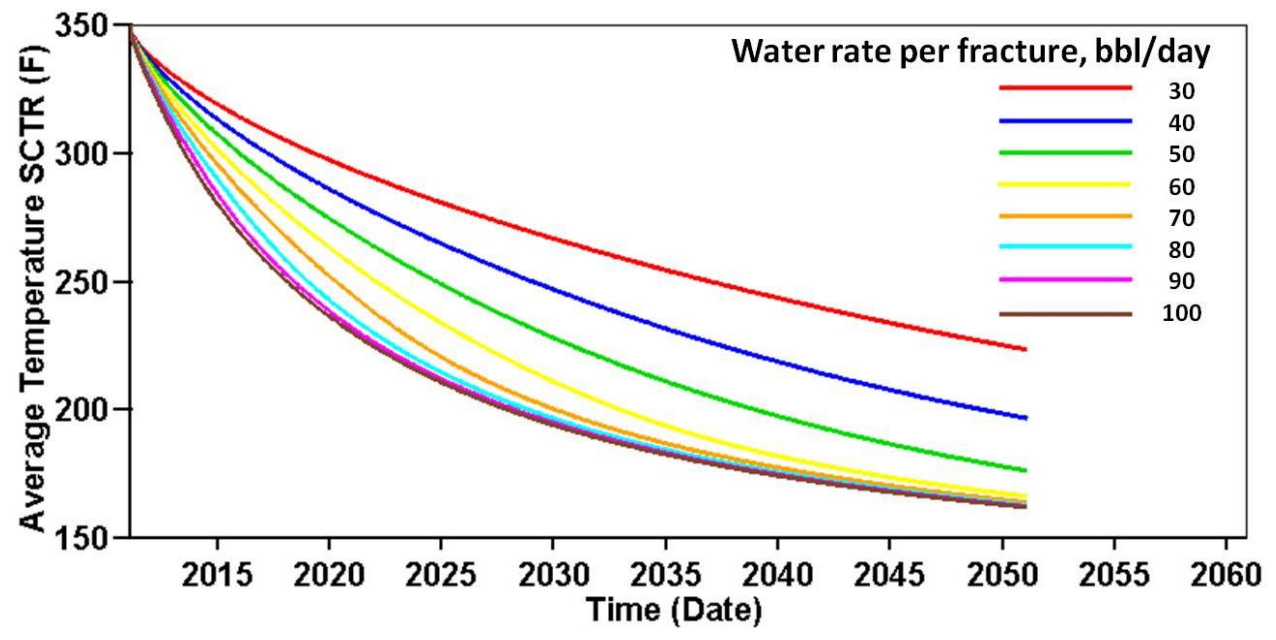

Figure 24: Plot showing higher drop in average temperature for higher flow rates.

\subsection{Binary cycle power plant design}

Three types of geothermal power plant technologies are currently being employed depending on the nature of the geothermal resource - Dry Steam, Flash Steam and Binary Cycle Power Plants. Dry Steam power plants directly run on steam which drives the turbine. Flash Steam power plants are more commonly employed and they require hydrothermal fluids at high pressure and temperature (above $360^{\circ} \mathrm{F}$ ) for operation. The hot fluids are flashed into flash tanks operated at lower pressure than that of the fluid. Flashing causes the fluid to vaporize and the generated vapor then drives the turbine. The non-vaporized fluid can be flashed again to generate additional electricity. Binary Cycle Power Plants operate with moderately hot hydrothermal fluids (below $400^{\circ} \mathrm{F}$ ). The hot fluid from the production well will exchange heat with working fluids having lower boiling point than water. The vaporized working fluid drives the turbine. No fluid is released into the atmosphere at all the times of operation. Low to moderate 
temperature formations are more common in nature, thus increasing the scope of usage of these power plants for geothermal heat extraction (Knaus et al. 2010). We used AspenHYSYS software for designing the basic binary and dual pressure binary power plants as shown in Figure 25 and Figure 26 respectively.

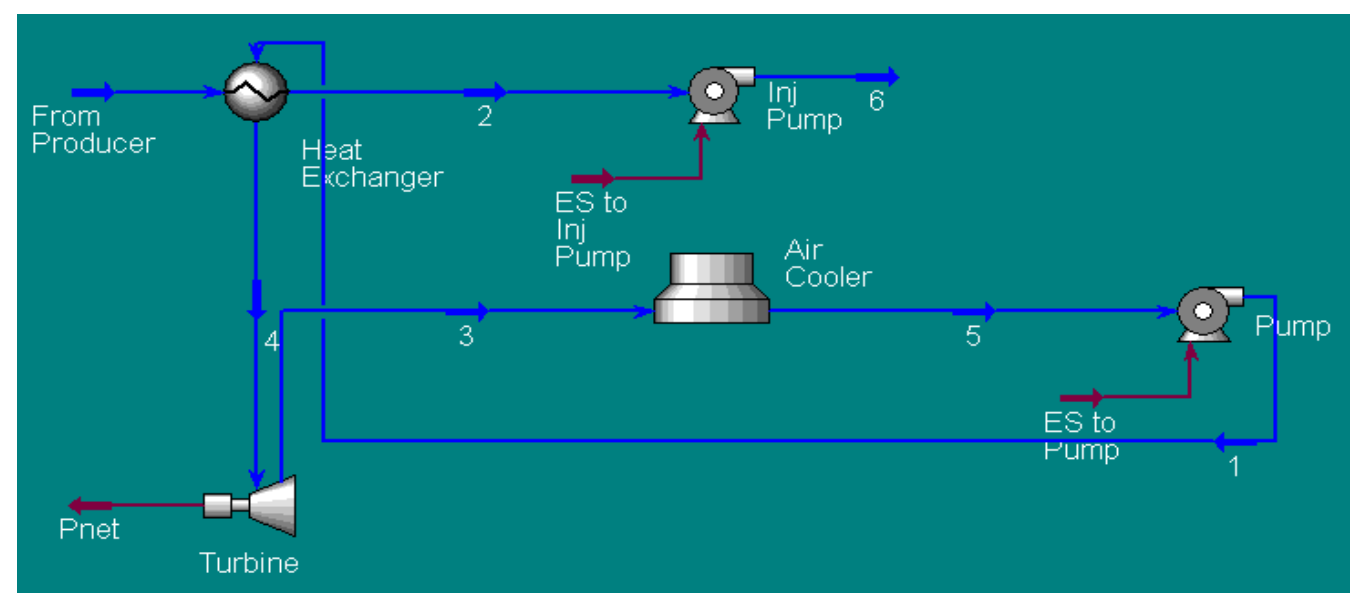

Figure 25: Basic binary power plant designed using AspenHYSYS.

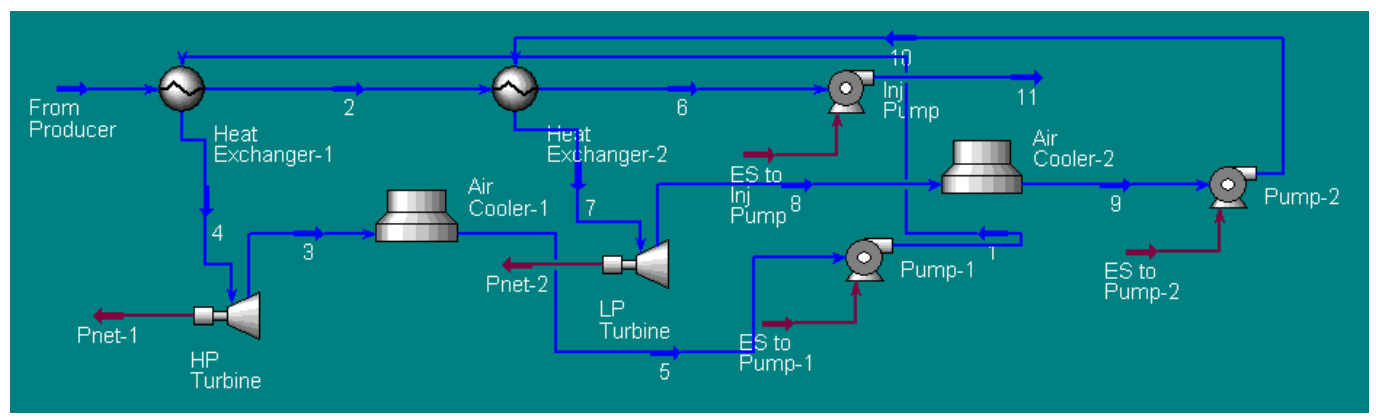

Figure 26: Dual pressure binary power plant designed using AspenHYSYS. 
The performance of the binary plant depends on the nature of its working fluid. Selection should mainly be based on its thermodynamic properties as well as its impact on health, safety and environment. Isopentane, which has a lower boiling point $\left(103^{\circ} \mathrm{F}\right)$ than water, was chosen as the working fluid. It has low toxicity but highly flammability. It has zero Ozone Depletion Potential (ODP) and Global Warming Potential (GWP) of 3 (with reference to $\mathrm{CO}_{2}$ 's GWP of 1). Power output was calculated for every $50^{\circ} \mathrm{F}$ temperature intervals starting from $350^{\circ} \mathrm{F}$ to $200^{\circ} \mathrm{F}$. The low efficiency of basic binary plant led us to consider a more efficient dual pressure binary cycle plant, in which the water passes through a series of heat exchangers one after the other (two in our case). Working fluid cycles downstream of the hot water line operate at lower pressures because the water temperature drops in every successive heat exchanger. Each working fluid cycle will add additional net power. Table 3 gives the details of the model inputs used in AspenHYSYS. Table 4 gives the details of number of wells required to meet the flow rate requirements of the power plant. 
Table 3: AspenHYSYS model inputs.

\begin{tabular}{|c|c|}
\hline Cooling method & Air Cooler \\
\hline Heat Exchanger & Shell and Tube type \\
\hline Working fluid & Isopentane \\
\hline \multicolumn{2}{|c|}{ Operating constraints } \\
\hline Plant type & Basic Binary \\
\hline Inlet water rate & $30,60,90,120(\mathrm{~kg} / \mathrm{s})$ \\
\hline Inlet temperature & $350,300,250,200\left({ }^{\circ} \mathrm{F}\right)$ \\
\hline Inlet pressure & $10000 \mathrm{psia}$ \\
\hline Plant type & Dual Pressure Binary \\
\hline Inlet water rate & $30,60,90,120(\mathrm{~kg} / \mathrm{s})$ \\
\hline Inlet temperature & $350^{\circ} \mathrm{F}$ \\
\hline Inlet pressure & $10000 \mathrm{psia}$ \\
\hline
\end{tabular}

Table 4: Number of wells required to meet the power plant feed rates.

\begin{tabular}{|c|c|c|c|}
\hline Plant feed rate & \multicolumn{3}{|c|}{ Number of well doublets for each per fracture rate } \\
\hline $\left.\mathbf{q}_{\mathbf{w}} \mathbf{( k g} / \mathbf{s}\right)$ & $\mathbf{3 0} \mathbf{b p d}$ & $\mathbf{4 0} \mathbf{b p d}$ & $\mathbf{5 0}$ bpd \\
\hline 30 & 8 & 6 & 5 \\
\hline 60 & 16 & 12 & 10 \\
\hline 90 & 23 & 18 & 14 \\
\hline 120 & 31 & 23 & 19 \\
\hline
\end{tabular}

Figure 27 shows the dependence of power output for basic binary and dual pressure binary plants on plant feed temperature. We observe that the net power generated by the plant decreases with decrease in feed temperature. Switching from basic binary to dual pressure binary increases the net power generated by the system substantially. 


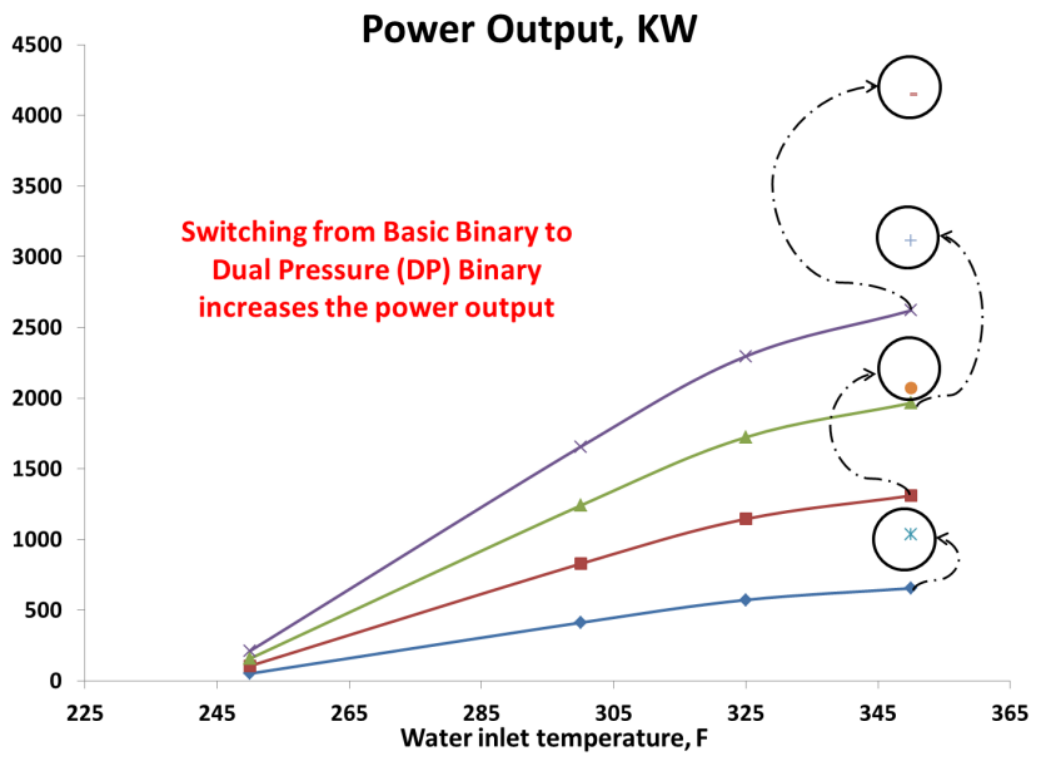

Figure 27: Net power from basic binary and dual pressure binary power plants for different water flow rates. 


\subsection{Economics}

The Geothermal Energy Association (GEA) website provides useful information for estimating geothermal project economics. Geothermal power plants are capital intensive but they require low operation and maintenance costs and need no fuel costs. On the other hand, gas fired power plants require less capital but more operating costs in terms of fuel requirements. Use of geothermal energy can help to decrease a country's dependence on unstable fossil fuel markets. The Levelized Cost of Electricity (LCOE) in Equation (13) enables comparison of alternative technologies which have different operational investment and period of operation. The total life cycle cost includes initial investment, fuel cost, operation and maintenance costs, cost of capital etc.

$L C O E=\frac{N P V \text { of Total life cycle cost }}{\text { Total life time energy production }}$

We studied the economics of the current project using the Department of Energy’s (DOE) Geothermal Electricity Technology Evaluation Model (GETEM). Because we propose to reuse existing shale gas wells to provide the SRV, exploration, drilling and stimulation costs were set to zero. The GETEM model was run for the case of a 5 MW Dual Pressure Binary Power Plant requiring input water feed of $120 \mathrm{~kg} / \mathrm{s}$. In 2007 the California Energy Commission (CEC) estimated LCOE for a 50 MW binary geothermal plant to be $\$ 92$ per megawatt hour (GEA website). Figure 28 shows the LCOE values for different technologies. We estimate that the LCOE for the binary geothermal plant proposed for our project is $\$ 72.87$ per megawatt hour. 


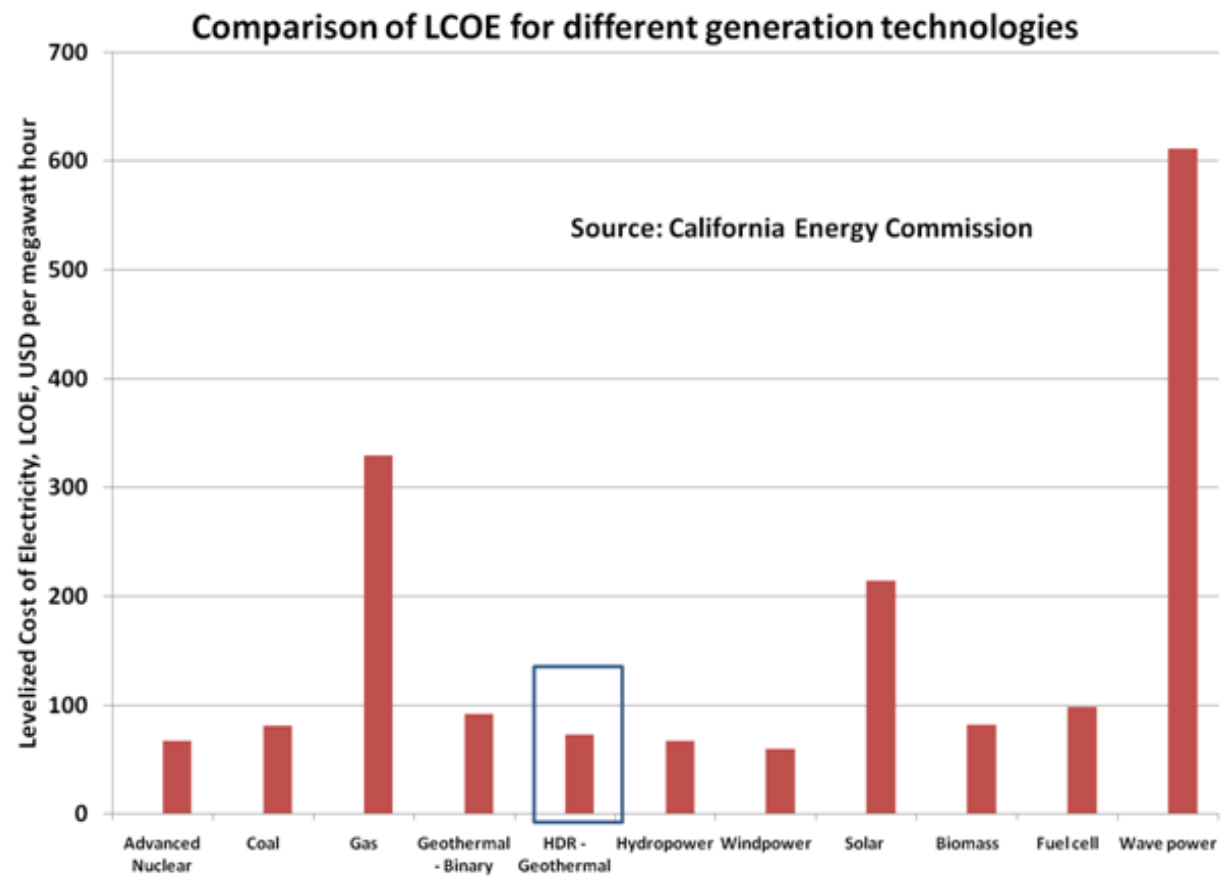

Figure 28: LCOE values for different energy generation technologies. LCOE value for HDR - Geothermal was estimated to be $\$ 73$ per megawatt hour. 


\subsection{Results and discussion}

The analytical model is a simple heat transfer problem with temperature as the only variable whereas the numerical model incorporates pressure which puts limits on several operational variables. We used this model to provide a quick estimate of power output and to study the effect of injection rate and number of fractures on the power output. On the other hand, numerical model presents a better picture of the heat extraction problem. Both the models were tested for various per fracture flow rates starting from $30 \mathrm{bpd}$ to $100 \mathrm{bpd}$. For an operational period of 40 years, the power output resulting from per fracture flow rates of $30 \mathrm{bpd}, 40 \mathrm{bpd}$ and $50 \mathrm{bpd}$ is almost constant. It is ideal to flow at these rates as the resulting power output is almost constant throughout the operation. Higher injection rates can be detrimental to power plant operation. In addition, the sensitivity of water outlet temperature to fracture spacing showed that decreasing the fracture spacing increases the rate of energy recovery from the system but accelerates the drop in water outlet temperature. Figure 29 shows a comparison plot of water outlet temperature variation with time for analytical and numerical models. The plot shows that for a particular value of per fracture flow rate, the drop in water outlet temperature is more in case of numerical model when compared to analytical model. Analytical model assumes constant water properties in the fracture, which in reality vary with pressure and temperature. Hence numerical model is closer to reality.

Numerical simulation suggests higher per fracture flow rates can be achieved by lowering the bottom hole pressure. This option may be uneconomical as the surface compression costs for reinjection increase with the decrease in producer bottom hole 
pressure. Producing the fluids at higher pressure prevents calcite and silica scaling in the pipelines, preheaters and heat exchangers downstream of the producer well. Moderate resource temperatures suggest using binary cycle power plants for heat extraction from hot water. A dual pressure binary power plant proved to be more efficient when compared to a basic binary plant. Economics of the project evaluated using the DOE GETEM tool estimated an LCOE for the HDR project of \$73 per megawatt hour which is competitive with currently used power generation options. The use of existing shale gas wells after they run out of gas production is a major factor in the project economics.

This chapter demonstrates feasibility of using the SRV for low grade geothermal power production by reusing shale gas wells. The next chapter reverses the heat transfer mechanism and investigates use of the SRV for heating an oil shale formation.

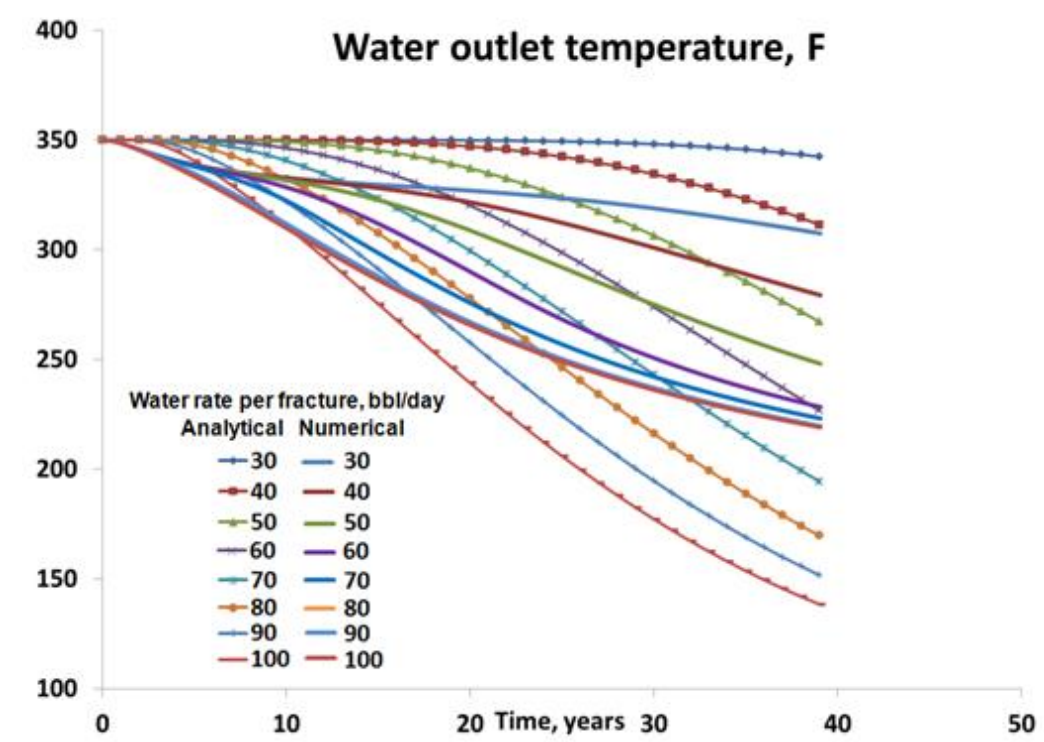

Figure 29: Comparison of water outlet temperature from analytical and numerical models for different per fracture flow rates. Analytical model assumes constant water properties in the fracture, which in reality vary with pressure and temperature. 


\section{CHAPTER III}

\section{USING MTFHW FOR HEATING OIL SHALE}

Chapter III discusses the concept of using MTFHW for heating oil shale. Analytical and numerical models similar to the models developed in Chapter II for geothermal heat extraction are applied this time to heat the oil shale. The chapter begins by explaining the procedure adopted for use of these models. Modeling the SRV for both the applications, heat extraction from shale and heating oil shale is the same except for the SRV dimensions. While heat extraction for geothermal power production is designed to supply energy to the power plant for decades, oil shale must be heated in a short time because there is no revenue from the oil shale project until the kerogen conversion has

occurred. Hence, heating oil shale requires a smaller SRV with smaller fracture spacing and half length.

\subsection{Description of MTFHW's SRV}

Figure 30 shows horizontal well configuration that is used for heating oil shale. The well configuration is similar to the one used for geothermal heat extraction expect for the fact that a smaller SRV is considered in this case. Figure 31 shows the injection and production well pattern used for heating oil shale. The yellow shaded region between the horizontal wells denotes volume of the heated region. 


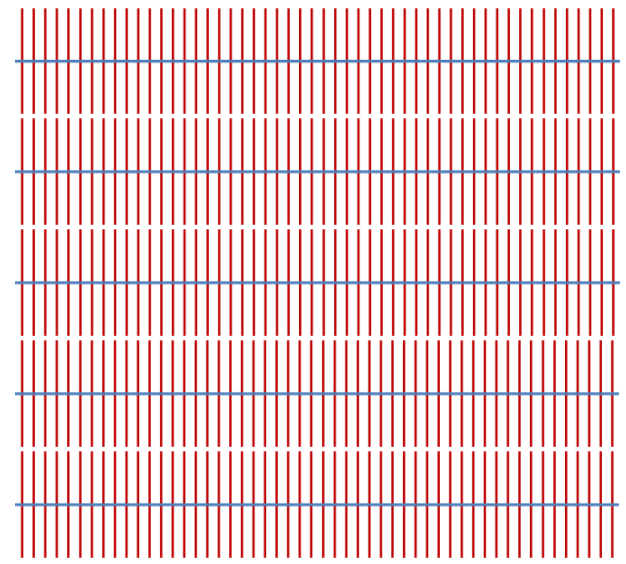

Figure 30: Idealization of horizontal well array for heating oil shale. The well configuration is similar to one proposed for geothermal heat extraction in Chapter II.

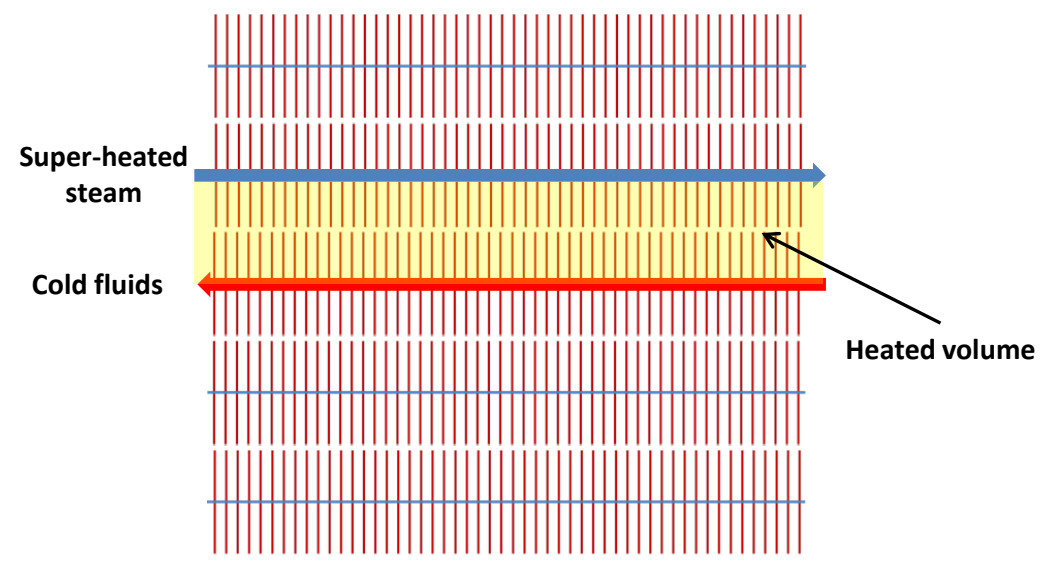

Figure 31: Diagram showing injection and production well pattern for heating oil shale.

Figure 32 shows the dimensions of the base case MTFHW well SRV designed to heat the oil shale. Well is $4000 \mathrm{ft}$ long, individual fractures are $25 \mathrm{ft}$ apart, fracture halflength and the fracture height are $50 \mathrm{ft}$ each. 


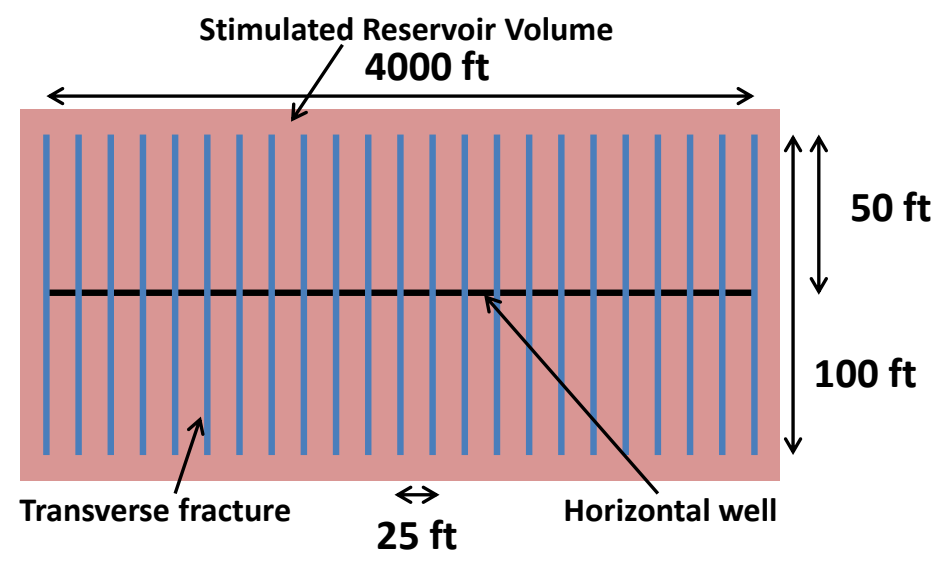

Figure 32: Typical SRV dimensions for heating oil shale. A smaller SRV is chosen for this purpose.

\subsection{Analytical model implementation}

This section describes the analytical model used for modeling the oil shale heating process. The process is similar to modeling geothermal heat extraction except that super-heated steam, instead of cold water, is the heat transmission fluid. The previous analytical model is used to model the series of parallel equally spaced transverse fractures of uniform width '2b', as shown in Figure 33. We assume the fractures are in impermeable blocks having homogeneous and isotropic properties. A rectilinear coordinate system was set in such a way that the $\mathrm{x}$-axis is perpendicular to the fractures and the y-axis passes midway between the matrix blocks. As before a single fracture is modeled, and we assume all fractures behave in a similar way. The plane of the fracture is oriented along the $\mathrm{z}$-axis. Interference between adjacent fractures imposes insulated boundaries exist at a distance of ' $\mathrm{x}_{\mathrm{e}}$ ' in either direction. Steam at temperature $\mathrm{T}_{\text {in }}$ is injected from one end of the fracture and cold water is recovered at the other end. 
The initial rock temperature was ' $\mathrm{T}_{\mathrm{ri}}$ ' and its thermal conductivity ' $\mathrm{k}_{\mathrm{r}}$ ' are constant in space. Mass and volumetric flow rate of the injected water is assumed constant. Product of the density $(\rho)$ and heat capacity $(C)$ for the rock is assumed constant. Heat transfer takes place only through conduction in the horizontal direction parallel to the $\mathrm{x}$-axis and through convection along the $y$-axis in the fracture. The steam temperature was assumed to be uniform across the width of the fracture and equal to the temperature of the rock at $\mathrm{x}=\mathrm{b}$ for all times.

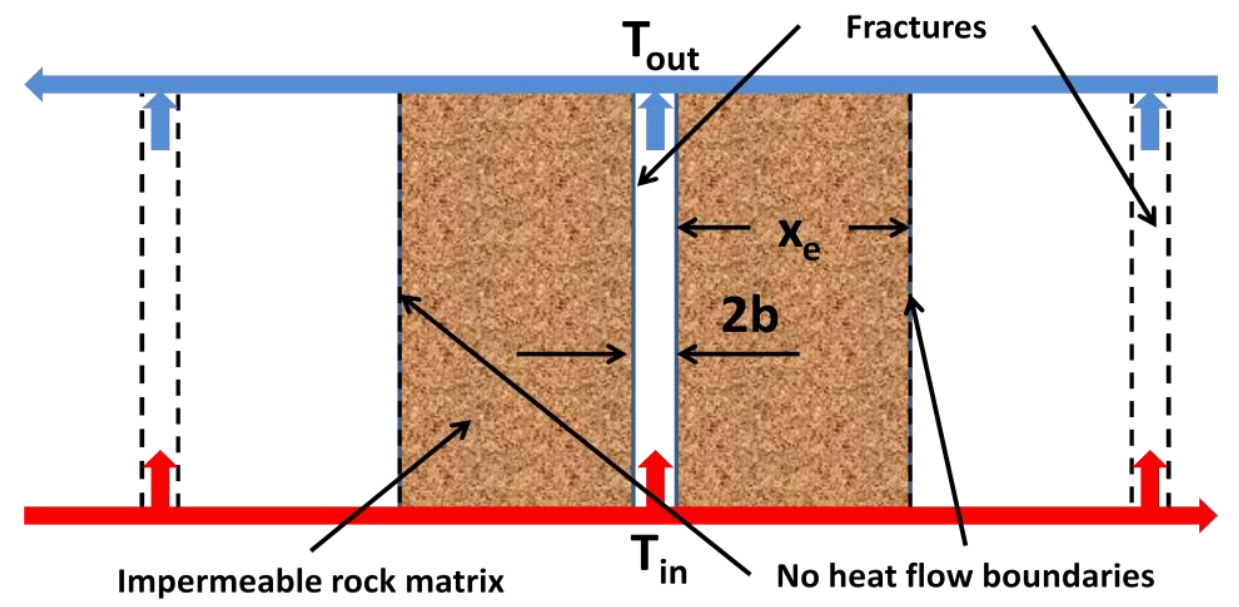

Figure 33: Analytical model for a single fracture unit.

Equations (1) to (7) still apply for the case of heating oil shale. However, a different approach was used for solving these differential equations. Previously, the solving procedure adopted for modeling geothermal heat extraction generated water outlet temperature from the fracture as a function of time. In this case, it is more meaningful to analyze the rock temperature as a function of distance perpendicular to the 
plane of the fracture. Derivation of the rock temperature as a function of distance perpendicular to the fracture using the previous method was difficult, but still possible. The solution is the rock temperature variation with distance perpendicular to the fracture and is given by Equation (14). The geothermal gradient is neglected in this model. Table 5 indicates the inputs for the analytical model.

$$
\begin{aligned}
T=\frac{q x_{e} T^{\prime}}{k_{r} \pi^{\frac{1}{2}}}\left(\operatorname{Erf}\left[\frac{x_{e}+x}{2 x_{e} T^{\frac{1}{2}}}\right]+\operatorname{Erf}\left[\frac{x_{e}-x}{2 x_{e} T^{\frac{1}{2}}}\right]\right) \\
-\frac{q x_{e} T^{\prime}}{k_{r} \pi^{\frac{1}{2}}}\left(\frac{x_{e}+x}{2 x_{e} T^{\frac{1}{2}}} \text { ExpIntegralEi }\left[-\frac{x_{e}+x^{2}}{4 x_{e}^{2} T^{\prime}}\right]\right) \\
-\frac{q x_{e} T^{\prime}}{k_{r} \pi^{\frac{1}{2}}}\left(\frac{x_{e}-x}{2 x_{e} T^{\frac{1}{2}}} \text { ExpIntegralEi }\left[-\frac{x_{e}-x^{2}}{4 x_{e}^{2} T^{\prime}}\right]\right)
\end{aligned}
$$

$k=\frac{k_{r}}{\rho_{r} c_{r}}$

$T^{\prime}=\frac{k t_{c}}{x_{e}{ }^{2}}$

where,

$T$, rock temperature at a distance ' $\mathrm{x}$ ' perpendicular to the plane of fracture at time ' $\mathrm{t}$ '; $q$, rate of heat supply per unit area per unit time;

$x_{e}$, fracture spacing;

$k_{r}$, thermal conductivity of rock;

$\rho_{r}$, density of rock;

$c_{r}$, specific heat of rock; 
Table 5: Analytical model inputs for heating oil shale.

\begin{tabular}{|c|c|c|}
\hline \multicolumn{3}{|c|}{ Reservoir properties } \\
\hline $\mathrm{T}_{\mathrm{ri}},{ }^{\circ} \mathrm{F}$ & Initial temperature & 104 \\
\hline $\mathrm{k}_{\mathrm{r}}, \mathrm{Btu} / \mathrm{ft}-\mathrm{day}-{ }^{\mathrm{O}} \mathrm{F}$ & Thermal conductivity & 24.36 \\
\hline$\rho_{\mathrm{r}}, \mathrm{lb} / \mathrm{ft}^{3}$ & Density & 107 \\
\hline $\mathrm{c}_{\mathrm{r}}, \mathrm{Btu} / \mathrm{lb}-{ }^{\circ} \mathrm{F}$ & Specific heat & 0.391 \\
\hline \multicolumn{2}{|c|}{ Well and stimulated fracture properties } \\
\hline $\mathrm{y}_{\mathrm{f}}, \mathrm{ft}$ & Fracture half-length & 50 \\
\hline $2 \mathrm{x}_{\mathrm{e}}, \mathrm{ft}$ & Fracture spacing & 25 \\
\hline $\mathrm{h}, \mathrm{ft}$ & Fracture height & 50 \\
\hline $\mathrm{q}, \mathrm{Btu} / \mathrm{s}$ & Heat injection rate & 110.55 \\
\hline
\end{tabular}

\subsubsection{Results and discussion}

This section discusses the analytical and numerical model results for oil shale SRV heating. Figure 34 shows plot of rock temperature variation with distance perpendicular to the fracture. From the plot, it is clear that the SRV can easily be heated to a temperature in the range $550-700^{\circ} \mathrm{F}$ within a period of 2 years. Mathematica code was developed for generating the rock temperature as a function of distance from the fracture. 


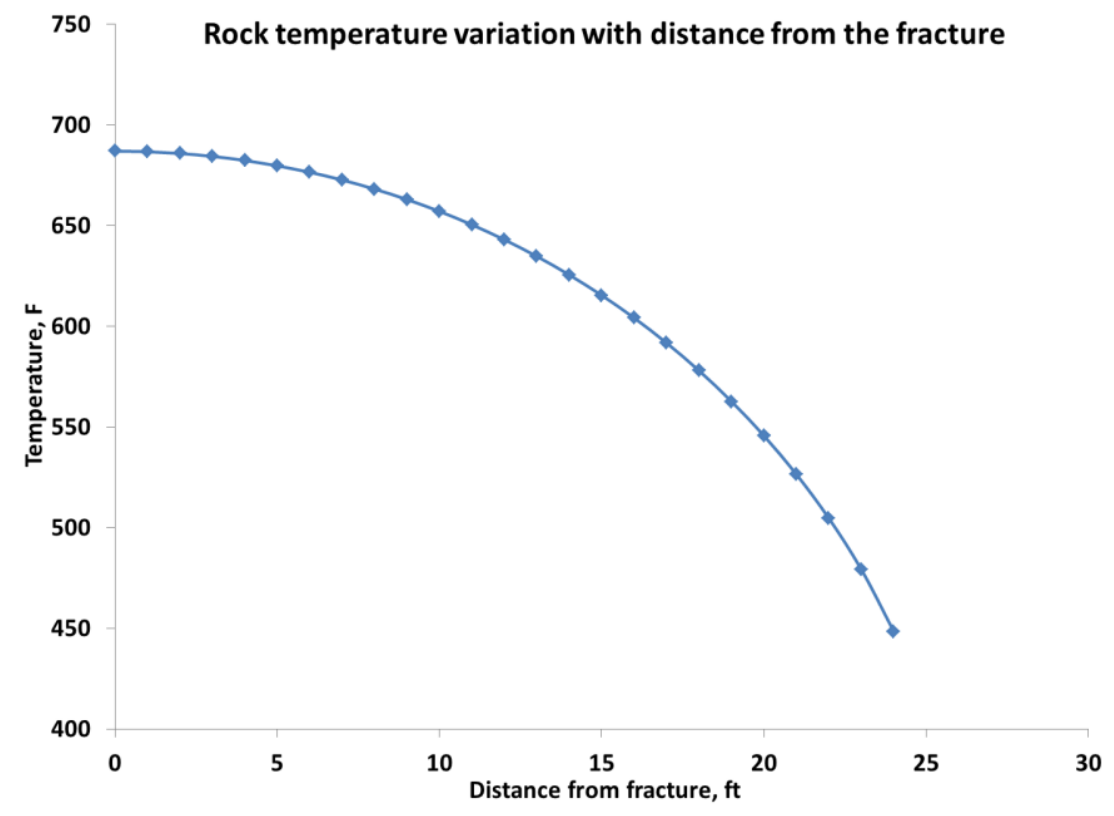

Figure 34: Plot showing rock temperature as a function of distance from the fracture after 2 years of continuous heating.

\subsubsection{Shell's In-situ Conversion Process (ICP)}

This section provides a brief introduction to Shell's technology for heating oil shale. The method will be discussed in light of oil shale development in Green River Formation which is the largest oil shale deposit in the world. It is located in the rocky mountain region of United States. Figure 35 shows a simplified picture of the ICP. It employs electric heaters for heating oil shale. Heating the oil shale pyrolyzes the kerogen in the rock to oil and gas products. These products are processed at the surface using conventional processing techniques. Oil shale deposits occur at shallow depths and in order to contain the zone of heating within the oil shale deposit, a freeze wall is constructed which isolates it from reaching ground water. Vertical holes are drilled $8 \mathrm{ft}$ apart and at a distance of $125 \mathrm{ft}$ away from the deposit all around it. Chilled aqua 
ammonia solution (refrigerant) at an approximate temperature of $-45^{\circ} \mathrm{F}$ is circulated through the well for a period of 6-12 months. The refrigerant freezes the water bearing intervals. The freeze wall acts as a barrier between the oil shale and ground water. Inward growth of the freeze wall is stopped by the heater wells drilled inside the containment area. 10 dewatering wells are drilled in the containment area which can later be used as producer wells (Shen 2009).

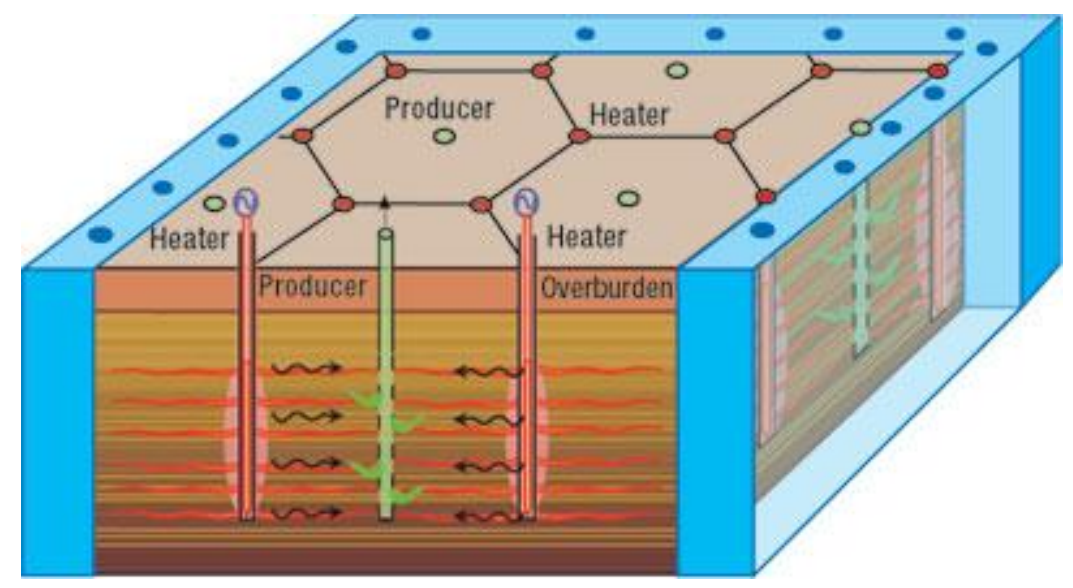

Figure 35: The above picture shows the producer and the heater well pattern in ICP process.

The heating process involves drilling 30 heater holes spaced $25 \mathrm{ft}$ apart. The surface area of such a heated pattern is $130 \mathrm{ft}$ by $100 \mathrm{ft}$. Oil shale is heated approximately for a period of 2 years. A total of approximately $600 \mathrm{STB} / \mathrm{d}$ of oil plus solution gas (or $1000 \mathrm{STB} / \mathrm{d}$ of oil equivalent) is produced from these wells. The temperature of the product is approximately $400^{\circ} \mathrm{F}$. Waste heat can be recovered from 
this fluid by passing it through a heat exchanger. The project claims to generate 3-4 times as much net energy as it consumes.

The method of using MTFHW for heating oil shale compares favorably to Shell's ICP both in terms of the time required to heat the oil shale and net energy generated. This thesis will conclude by presenting an estimate of initial oil in place considering the dimensions of the proposed SRV design. The well length was assumed to be $4000 \mathrm{ft}$ thus giving 160 equally spaced transverse fractures at $25 \mathrm{ft}$ fracture spacing. For oil shale heat capacity of $56.06 \mathrm{Btu} / \mathrm{ft}^{3}-\mathrm{F}$, the total amount of heat energy required to heat such a single fracture unit is estimated to be $7.10^{9} \mathrm{Btu}$. Assuming an average oil grade of $26.5 \mathrm{gal} / \mathrm{ton}$ for the Green River oil shale, the initial oil in place of the SRV is estimated to be $655,000 \mathrm{bbl}$ at reservoir conditions. For example, if we consider a recovery factor of $10 \%$, the total volume of oil recovered from the SRV is $65,520 \mathrm{bbl}$ at reservoir conditions. The energy content of one STB of the produced oil is $6.10^{6}$ Btu of combustion energy, giving $4 \cdot 10^{11}$ Btu in total.

\subsection{Numerical model development}

This section provides a brief description of the numerical model developed for a single fracture unit. The numerical model is similar to the one developed for geothermal heat extraction. A dual permeability model was used even though there no flow is taking place between the rock matrix and the fracture because the matrix permeability is effectively zero. The fracture is modeled at its true. A logarithmic refinement increasing in spacing away from the fracture enables the model to capture the thermal front 
movement in the fracture and in the rock matrix. Figure 36 shows the grid used in the simulation. Oil shale heating is an energy intensive process and it requires large amounts of heat to convert the immature organic matter into products of commercial value. Super-heated steam at a temperature of $750^{\circ} \mathrm{F}$ is used for heating the oil shale. A small modular reactor (SMR) is proposed for generating the super-heated steam. A brief description of the SMR is provided in the next section.

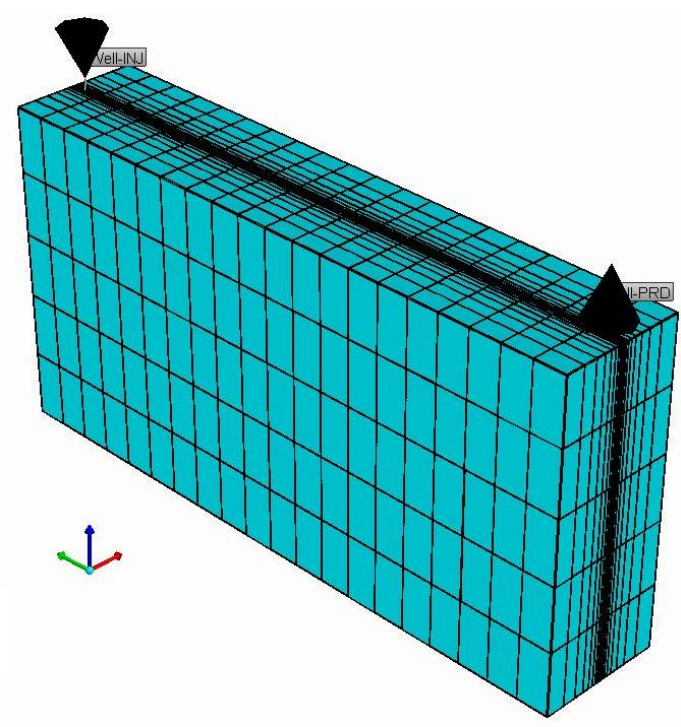

Figure 36: Numerical model for a single fracture unit designed using CMG. 
Table 6 gives the details of inputs used for the numerical model. Thermal properties of the oil shale rock were chosen from Prats and O'Brien (1975).

Table 6: Numerical model inputs for heating oil shale.

\begin{tabular}{|c|c|}
\hline \multicolumn{2}{|l|}{ Reservoir properties } \\
\hline Initial temperature, ${ }^{\circ} \mathrm{F}$ & 104 \\
\hline Reservoir pressure, psia & 714 \\
\hline Depth, $\mathrm{ft}$ & 870 \\
\hline Thermal conductivity, Btu/ft-day-F & 24.36 \\
\hline Heat capacity, Btu/ $/ \mathrm{ft}^{3}-\mathrm{F}$ & 56.06 \\
\hline Matrix porosity, fraction & 0.05 \\
\hline Matrix permeability, md & 1E-09 \\
\hline Fracture porosity (natural fracture), fraction & $2 \mathrm{E}-05$ \\
\hline Fracture permeability (natural fracture), md & $2 \mathrm{E}-05$ \\
\hline Rock compressibility, $1 / p s i$ & $1 \mathrm{E}-06$ \\
\hline $\begin{array}{l}\text { Initial water saturation } \\
\text { (matrix and propped fracture) }\end{array}$ & 0.8 \\
\hline \multicolumn{2}{|c|}{$\begin{array}{c}\text { Simulation model description } \\
\end{array}$} \\
\hline Grid model & LS-LR-DK grid \\
\hline Fracture model & Infinite conductivity \\
\hline Grid & $1 * 20 * 5$ \\
\hline Grid block dimensions & $25 \mathrm{ft} * 20 \mathrm{ft} * 10 \mathrm{ft}$ \\
\hline $\begin{array}{c}\text { Local grid refinement } \\
\text { ( } \log \text { refinement in } x \text {-direction) }\end{array}$ & $19 * 4 * 1$ \\
\hline SRV dimensions & $20 \mathrm{ft} * 100 \mathrm{ft} * 50 \mathrm{ft}$ \\
\hline
\end{tabular}

\subsubsection{Results and discussion}

Figure 37 shows the thermal front propagation in the matrix and in the fracture. Tracking the thermal front is very important for both the applications in order to avert premature breakthrough of cold water in producer wells in geothermal heat extraction and to avoid premature steam front breakthrough in producer wells in the process of 
heating oil shale. The phenomenon can have detrimental effects on the efficiency of the whole system. From Figure 37, it can be seen that the rate of thermal front propagation along the fracture is faster at the initial stages of injection with little or no heat transfer into the matrix. The rate of heat transfer along the fracture decreases with time and the rate of heat transfer in the matrix increases. The thermal front diffusion into the matrix can clearly be seen in Figure 37. A uniform energy sweeping mechanism will exist from the point where the rate of heat transfer in the matrix and the fracture become equal. For both the applications, we consider flowing at lower flow rates in order to achieve the state of uniform energy sweeping in a short period.

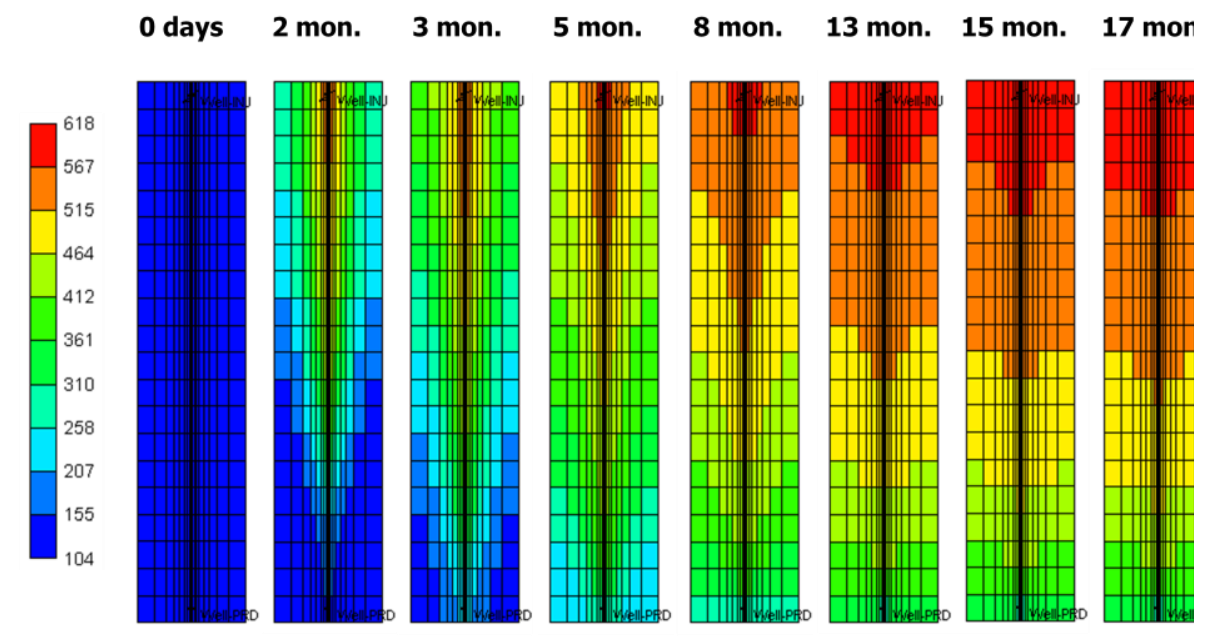

Figure 37: Illustration of thermal front propagation in matrix and fracture. 


\subsection{Using a Small Modular Reactor for generating super-heated steam}

Large volume of steam at high temperature is required to heat oil shale to temperatures as high as $700^{\circ} \mathrm{F}$. Conventional steam generators cannot generate steam at such high temperatures. In our project, we propose to use an SMR, which has the capability of supplying steam at temperatures as high as $1000^{\circ} \mathrm{C}$. SMR has its advantages over larger nuclear reactors in that it can easily be assembled in a ware house, has less construction time. It involves less capital and operational costs. SMR power output ranges between 100-300 MW. The process heat can be directly utilized for heating oil shale. Little or no $\mathrm{CO}_{2}$ is emitted during the process. SMR can further be used for generating electricity and hydrogen during hours of non-heating. Figure 38 shows picture of typical very high temperature nuclear reactor. 


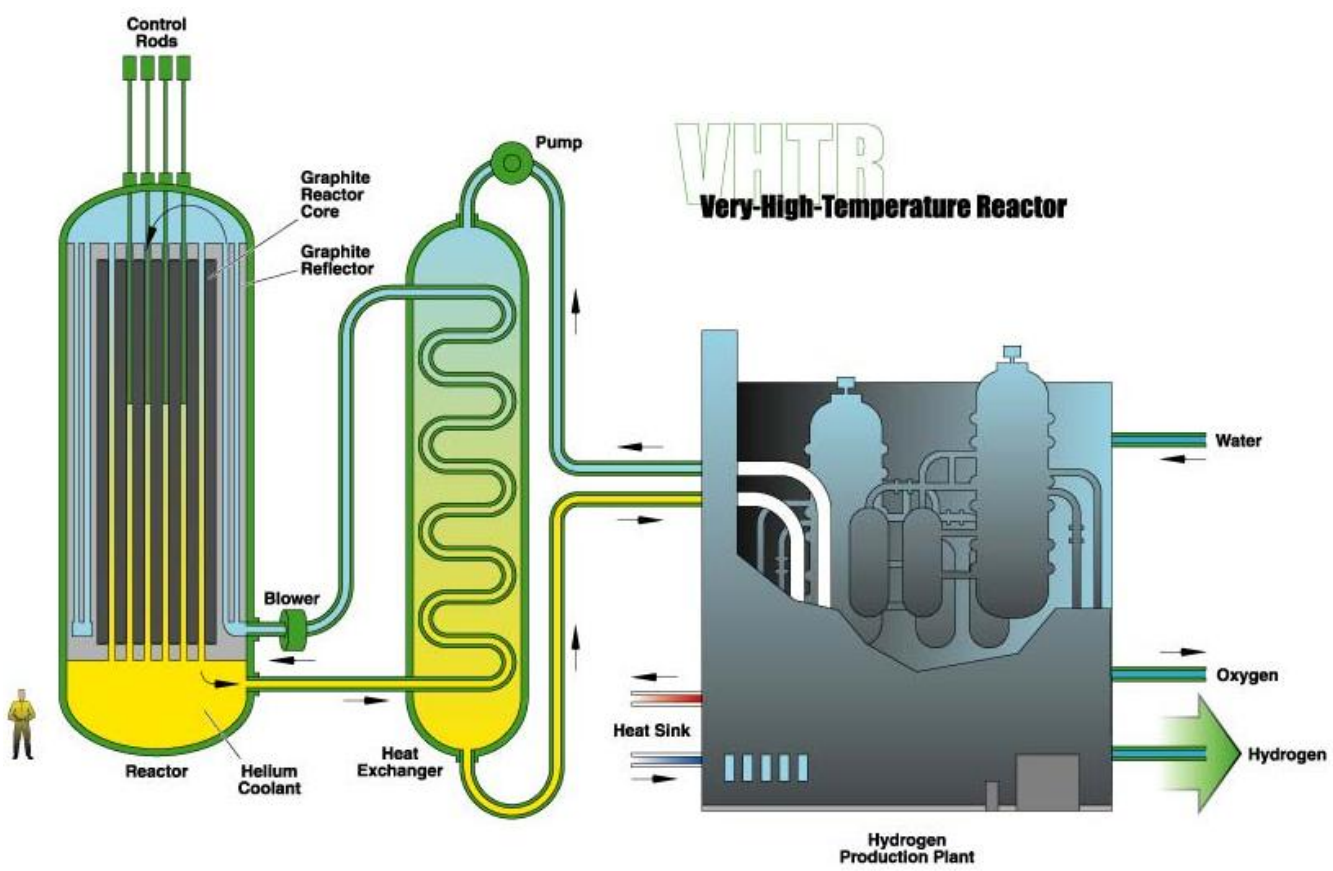

Figure 38: SMR for generating super-heated steam. 


\section{CHAPTER IV}

\section{CONCLUSIONS}

This chapter contains the summary of the contents presented in this thesis along with conclusions and future work.

\subsection{Summary}

This thesis mainly focused on the aspects of geothermal heat extraction from HDR and the method of using MTFHW array for heating oil shale. The first application focused on using an array of horizontal wells for geothermal heat extraction from Haynesville Shale. Based on the previous research work on heat extraction from HDR, an analytical model was developed for modeling the heat extraction process. A single fracture unit, which is the building block of SRV, was considered for this purpose. The fracture unit can ideally be considered as having constant energy because there is no heat transfer between the SRV and the outer rock matrix. The model was tested for sensitivity of water outlet temperature to fracture number (and hence fracture spacing) and flow rates. It was observed that decreasing the fracture spacing increases the drop in water outlet temperature and hence the rate of energy extraction from the fracture unit increases. Increasing the flow rate increases the rate of energy extraction from the fracture unit and hence decreases the life of the resource.

A more realistic numerical model was developed using STARS module of CMG software. The model incorporates the features of both DK and MINC models. Similar 
conclusions were drawn using this model. The importance of producing the fluids at higher pressures was demonstrated in this thesis. The process of re-injection will be uneconomical if one plans to produce higher volumes of water by lowering the bottomhole pressure beyond a certain limit. Lower bottom hole pressures result in higher compression costs of the reinjection water at the surface. From the developed analytical and numerical models, we concluded that it is more economical to produce at lower rates and at high bottom-hole pressure even if it results in lower power output. Producing the hot water as a pressurized liquid by means of down-hole pumps eliminates the possibility of calcite and silica scaling in surface equipment and pipelines. Moderate resource temperature made us use a Binary Cycle Power Plant at the surface. A basic binary power plant was designed with isopentane as the secondary working fluid and air cooler as the cooling medium. The efficiency of the power plant was increased by using heat exchangers in series, which resulted in greater water outlet temperature drop and hence higher power output. The economics of the geothermal project was studied using DOE's GETEM tool. The cost of producing electricity using our process was estimated to be around $\$ 73$ per megawatt hour.

The second application focused on using a similar horizontal well array for heating oil shale. Analytical and numerical models were developed for studying the heat transfer. Saturated super-heated steam was used for heating oil shale. The models showed that the SRV of a typical oil shale can be heated in a time period of 2 years. We proposed to use a SMR for generating the super-heated steam. We discussed the benefits of using SMR for generating the steam. 


\subsection{Conclusions}

The following conclusions can be drawn from this thesis:

1. Analysis coupling both analytical and numerical flow models with a model for a surface binary cycle power plant suggests that reuse of Haynesville Shale gas production wells for low grade geothermal heat extraction after gas production is depleted appears feasible both technically and economically.

2. Provided that sufficient connectivity can be achieved between adjacent wells, project economics are greatly aided by eliminating well drilling and completion costs. The number and spacing of hydraulic fractures created for the original purpose of shale gas production is adequate for geothermal heat extraction as well.

3. The power plant model indicated that a dual pressure binary plant is more efficient and results in higher power output when compared to a basic binary cycle power plant by enabling a higher drop in water outlet temperature in the heat exchanger and hence more power output. The estimated LCOE of $\$ 73$ per megawatt hour compares favorably to a natural gas power plant.

4. Analytical and numerical models demonstrate the success of using MTFHW array for heating oil shale.

5. SMR technology is a very promising option for generation of super-heated steam that is necessary for heating oil shale. 


\subsection{Future work}

The analytical and numerical models developed in earlier sections made the basic assumption of impermeable matrix blocks so that there is no flow between the matrix and the fracture. A more general inter granular fluid flow model is required to move closer to reality and this can be achieved by assigning finite values to permeability and porosity of the rock matrix. Heat transfer between the rock matrix and the fracture can now take place by convection in addition to conduction.

Thermal contraction of the rock results in the creation of new cracks, creating pathways for the water to reach the uncontacted perimeter of the hot rock. The power output is enhanced due to increase in convection heat transfer between water and hot rock (apart from conduction), preferential crack penetration towards hotter zones in the reservoir, greater hot rock volume available for heat transfer and fracture width increase due to rock contraction. Loss of water can be a major problem during circulation due to unexpected fracture growth, making it difficult to maintain pressure at the desired level for injection of hot water. Hence there is a need to develop more generalized thermalgeomechanical-chemical coupled model to completely study the process of heat extraction from HDR systems.

The method of using MTFHW for heating oil shale will be compared to Shell's ICP in terms of time required to heat the oil shale and net energy generated in our future endeavors. 


\section{REFERENCES}

Abé, H., Duchane, D.V., Parker, R.H., and Kuriyagawa, M. 1999. Present Status and Remaining Problems of HDR/HWR System Design. Geothermics 28 (4-5): 573590.

Baria, R., Baumgärtner, J., Gérard, A., Jung, R., and Garnish, J. 1999. European HDR Research Programme at Soultz-Sous-Forêts (France) 1987-1996. Geothermics 28 (4-5): 655-669.

Bodvarsson, G. 1969. On the Temperature of Water Flowing through Fractures. JGR 74 (8): 1987-1992.

Bodvarsson, G. 1974. Geothermal Resource Energetics. Geothermics 3 (3): 83-92.

Bödvarsson, G.S. and Tsang, C.F. 1982. Injection and Thermal Breakthrough in Fractured Geothermal Reservoirs. JGR 87 (B2): 1031-1048.

Crawford, P., Biglarbigi, K., Dammer, A., and Knaus, E. 2008. Advances in World OilShale Production Technologies. Paper SPE 116570 presented at the SPE Annual Technical Conference and Exhibition, Denver, Colorado, 21-24 Spetember.

Cuenot, N., Faucher, J.P., Fritsch, D., Genter, A., and Szablinksi, D. 2008. The European EGS Project at Soultz-Sous-Forets: From Extensive Exploration to Power Production. Paper presented at the 2008 IEEE Power and Energy Society General Meeting, Pittsburgh, Pennsylvania, 20-24 July, Pages 1-8.

Duchane, D.V. 1995. Hot Dry Rock Geothermal Energy in the USA: Moving Toward Practical Use. Paper presented at the 1995 World Geothermal Congress, Florence, Italy, 18-31 May, Pages 1-6.

Duchane, D.V. 1996. Geothermal Energy from Hot Dry Rock: A Renewable Energy Technology Moving Towards Practical Implementation. Renewable Energy 9 (14): 1246-1249.

Edwards, L.M., Chilingar, G.V., Rieke, H.H. and Fertl, W.H. 1982. Handbook of Geothermal Energy, Houston, Texas, Gulf Publishing Co.

Fisher, M.K., Heinze, J.R., Harris, C.D., Davidson, B.M., Wright, C.A. et al. 2004. Optimizing Horizontal Completion Techniques in the Barnett Shale Using Microseismic Fracture Mapping. Paper SPE 90051 presented at the SPE Annual Technical Conference and Exhibition, Houston, Texas, 26-29 September. 
Gringarten, A.C., Witherspoon, P.A., and Ohnishi, Y. 1975. Theory of Heat Extraction from Fractured Hot Dry Rock. JGR 80 (8): 1120-1124.

Harlow, F.H. and Pracht, W.E. 1972. A Theoretical Study of Geothermal Energy Extraction. JGR 77 (35): 7038-7048.

Knaus, E., Killen, J., Biglarbigi, K., and Crawford, P. 2010. Oil Shale: A Solution to the Liquid Fuel Dilemma, New York, Oxford University Press.

Mink, R. 2000. Kirk-Othmer Encyclopedia of Chemical Technology, Hoboken, New Jersey, John Wiley \& Sons, Inc.

Parker, R. 1999. The Rosemanowes HDR Project 1983-1991. Geothermics 28 (4-5): 603-615.

Pope, C.D., Palisch, T.T., Lolon, E., Dzubin, B., and Chapman, M.A.. 2010. Improving Stimulation Effectiveness: Field Results in the Haynesville Shale. Paper SPE 134165 presented at the SPE Annual Technical Conference and Exhibition, Florence, Italy, 20-22 September.

Prats, M. and O'Brien, S.M. 1975. The Thermal Conductivity and Diffusivity of Green River Oil Shales. JPT 27 (1): 97-106.

Pruess, K. and Bodvarsson, G.S. 1984. Thermal Effects of Reinjection in Geothermal Reservoirs with Major Vertical Fractures. JPT 36 (9): 1567-1578.

Rubin, B. 2010. Accurate Simulation of Non Darcy Flow in Stimulated Fractured Shale Reservoirs. Paper SPE 132093 presented at the SPE Western Regional Meeting, Anaheim, California, 27-29 May.

Shale Oil Extraction, 7 July, 2011. http://en.wikipedia.org.

Shen, C. 2009. Reservoir Simulation Study of an in-Situ Conversion Pilot of GreenRiver Oil Shale. Paper SPE 123142 presented at the SPE Rocky Mountain Petroleum Technology Conference, Denver, Colorado, 14-16 April.

Thompson, J.W., Fan, L., Grant, D., Martin, R.B., Kanneganti, K.T. et al. 2010. An Overview of Horizontal Well Completions in the Haynesville Shale. Paper SPE 136875 presented at the Canadian Unconventional Resources and International Petroleum Conference, Calgary, Alberta, 19-21 October.

Wang, J., and Liu, Y. 2011. Simulation Based Well Performance Modeling in Haynesville Shale Reservoir. Paper SPE 142740 presented at the SPE Production and Operations Symposium, Oklahoma City, Oklahoma, 27-29 March. 
Whitcombe, J.A. 1976. Oil Shale Development: Status and Prospects. JPT 28 (1): 16-20. 


\title{
APPENDIX
}

\section{Mathematica code of analytical model for geothermal heat extraction}

\author{
GWR [F_, t_, M_:32, precin_:0]:=Module [ \\ $\{\mathrm{M} 1, \mathrm{G} 0, \mathrm{Gm}, \mathrm{Gp}$, best, expr, $\tau=\log [2] / \mathrm{t}, \mathrm{Fi}$, broken, prec $\}$, \\ If $[$ precin $<=0, \operatorname{prec}=21 \mathrm{M} / 10$, prec $=$ precin]; \\ If $[\mathrm{prec}<=\$$ MachinePrecision, prec $=\$$ MachinePrecision]; \\ broken=False; \\ If $[$ Precision $[\tau]<$ prec, $\tau=$ SetPrecision $[\tau$,prec $]$; \\ Do $[\mathrm{Fi}[\mathrm{i}]=\mathrm{N}[\mathrm{F}[\mathrm{i} \tau]$,prec $],\{\mathrm{i}, 1,2 \mathrm{M}\}]$; \\ $\mathrm{M} 1=\mathrm{M}$; \\ Do $\left[\mathrm{G} 0[\mathrm{n}-1]=\tau(2 \mathrm{n}) ! /(\mathrm{n} !(\mathrm{n}-1) !) \operatorname{Sum}\left[\operatorname{Binomial}[\mathrm{n}, \mathrm{i}](-1)^{\wedge} \mathrm{i}\right.\right.$ Fi[n+i], $\left.\{\mathrm{i}, 0, \mathrm{n}\}\right]$ \\ If[Not[NumberQ[G0[n-1]]],M1=n-1;G0[n-1]=.; \\ Break[]]; \\ $,\{\mathrm{n}, 1, \mathrm{M}\}]$ \\ $\operatorname{Do}[\mathrm{Gm}[\mathrm{n}]=0,\{\mathrm{n}, 0, \mathrm{M} 1\}]$ \\ best $=\mathrm{G} 0[\mathrm{M} 1-1]$ \\ Do[ \\ Do[ \\ $\operatorname{expr}=\mathrm{G} 0[\mathrm{n}+1]-\mathrm{G} 0[\mathrm{n}]$ \\ If[Or[Not[NumberQ[expr]],expr==0],broken=True;Break[]];
}


$\operatorname{expr}=\mathrm{Gm}[\mathrm{n}+1]+(\mathrm{k}+1) / \mathrm{expr}$

$\mathrm{Gp}[\mathrm{n}]=\operatorname{expr} ;$

If[OddQ[k],If[n==M1-2-k,best=expr]];

$,\{\mathrm{n}, \mathrm{M} 1-2-\mathrm{k}, 0,-1\}]$

If[broken,Break[]];

$\operatorname{Do}[\mathrm{Gm}[\mathrm{n}]=\mathrm{G} 0[\mathrm{n}] ; \mathrm{G} 0[\mathrm{n}]=\mathrm{Gp}[\mathrm{n}],\{\mathrm{n}, 0, \mathrm{M} 1-\mathrm{k}\}] ;$

$,\{\mathrm{k}, 0, \mathrm{M} 1-2\}]$

best];

SetAttributes[GWR, $\{$ NHoldAll,Listable $\}]$;

$\$$ MaxExtraPrecision=5000;

Tro=176.67; $\left({ }^{*}\right.$ Initial rock remperature*)

Two=30; (*Injection fluid initial temperature*)

rhow $=1 ;\left(* \mathrm{~g} / \mathrm{cc}^{*}\right)$

$\mathrm{cw}=1 ;\left(* \mathrm{cal} / \mathrm{g} / \mathrm{C}^{*}\right)$

$\mathrm{kr}=0.0042 ;\left({ }^{*} \mathrm{Cal} / \mathrm{cm} / \mathrm{sec} / \mathrm{C}^{*}\right)$

rhor $=2.3 ;\left(* \mathrm{~g} / \mathrm{cc}^{*}\right)$

$\mathrm{cr}=0.391 ;\left({ }^{*} \mathrm{cal} / \mathrm{g} / \mathrm{C}^{*}\right)$

tc $=5 * 365 * 86400 ;\left(* \sec ^{*}\right)$

$\mathrm{t}=$ Table $\left[\mathrm{i},\left\{\mathrm{i}, 1, \mathrm{tc}, 365^{*} 86400\right\}\right]$;

$\mathrm{xe}=60.96 * 100 ;(* \mathrm{~cm} *)$

$\mathrm{z}=182.88 * 100 ;(* \mathrm{~cm} *)$

$\mathrm{H}=182.88^{*} 100 ;\left(* \mathrm{~cm}^{*}\right)$ 
$\mathrm{Q}=0.0241$;

Qlist $=\{0.0181,0.0241,0.0302,0.0362,0.0422,0.0483,0.0543,0.0603\}$;

$\mathrm{ht}=30.48 * 100$

$\operatorname{tds}=\left(\mathrm{t} \mathrm{Q}^{\wedge} 2(\text { rhow cw })^{\wedge} 2\right) /\left(\mathrm{H}^{\wedge} 24 \mathrm{kr}\right.$ rhor $\left.\mathrm{cr}\right)$;

$\operatorname{Twd}\left[\mathrm{s}_{-}\right]=(1 / \mathrm{s}) * \operatorname{Exp}[-(\mathrm{z} / \mathrm{H}) \operatorname{Sqrt}[\mathrm{s}] \operatorname{Tanh}[($ rhow cw Q xe)/(2 kr H) Sqrt[s]]];

$\mathrm{F}\left[\mathrm{s} \_\right]=$Rationalize$[\mathrm{Twd}[\mathrm{s}], 0]$;

$\mathrm{Tw}=\mathrm{N}[\mathrm{GWR}[\mathrm{F}, \mathrm{tds}]]$

Twreq=Tro-Tw* (Tro-Two);

$\{$ ttab,Twout $\}=\operatorname{Cases}\left[\{\mathrm{t}, \text { Twreq }\}^{\mathrm{T}}, \mathrm{e} \_/ ; 0<\mathrm{e}[[2]]<=\text { Tro }\right]^{\mathrm{T}}$;

val $=\{$ ttab, 32+(9 Twout $) / 5\}^{\mathrm{T}}$;

Export["data.dat",val]

TableForm[val,TableHeadings-> \{ None, $\{$ "t","Twout" \} \}]

ListPlot[val,FrameLabel->\{"t","Twout,K"\},Joined-> True,PlotStyle->Red,GridLines-

$>$ Automatic]

$f\left[x_{-}\right]=\operatorname{Fit}\left[\operatorname{val},\left\{1, x_{,} x^{\wedge} 2, x^{\wedge} 3, x^{\wedge} 4\right\}, x\right]$

nof $=20$;

$\mathrm{Hw}=4.184 *$ nof $*$ ht*rhow* $\mathrm{cw}^{*} \mathrm{Q} *$ Integrate $[\mathrm{f}[\mathrm{x}]-\mathrm{Two},\{\mathrm{x}, 0, \mathrm{tc}\}]$

$\mathrm{Pw}=\mathrm{Hw} /\left(\mathrm{tc}^{*} 10^{\wedge} 6\right)$ 


\section{Mathematica code of analytical model for heating oil shale}

$\mathrm{q}=0.015 ;\left(* \mathrm{cal} / \mathrm{cm}^{\wedge} 2 / \mathrm{sec}^{*}\right)\left({ }^{*}\right.$ Heat injection rate $\left.*\right)$

$\mathrm{kr}=0.0042 ;\left({ }^{*} \mathrm{Cal} / \mathrm{cm} / \mathrm{sec} / \mathrm{C}^{*}\right)$

rhor $=2.3 ;\left(* \mathrm{~g} / \mathrm{cc}^{*}\right)$

$\mathrm{cr}=0.391 ;\left({ }^{*} \mathrm{cal} / \mathrm{g} / \mathrm{C}^{*}\right)$

$\mathrm{tc}=2 * 365 * 86400$

$\mathrm{xe}=30.48 * 100$

$\mathrm{k}=\mathrm{kr} /($ rhor $\mathrm{cr})$;

$\mathrm{T}^{\prime}=(\mathrm{k} \mathrm{tc}) / \mathrm{xe}^{2}$

$\mathrm{x}=$ Table $[\mathrm{j},\{\mathrm{j}, 0.1, \mathrm{xe}, 30.48\}]$;

$\mathrm{T}=\left(\mathrm{q} \mathrm{xe} \mathrm{T}^{\prime}\right) /\left(\mathrm{kr} \mathrm{Pi}^{1 / 2}\right)\left(\operatorname{Erf}\left[(\mathrm{xe}+\mathrm{x}) /\left(2 \mathrm{xe} \mathrm{T}^{, 1 / 2}\right)\right]+\operatorname{Erf}\left[(\mathrm{xe}-\mathrm{x}) /\left(2 \mathrm{xe} \mathrm{T}^{, 1 / 2}\right)\right]-(\mathrm{xe}+\mathrm{x}) /(2 \mathrm{xe}(\mathrm{Pi}\right.$

$\left.\mathrm{T}^{\prime}\right)^{1 / 2}$ ExpIntegralEi[-((xe+x)$\left.\left.)^{2} /\left(4 \mathrm{xe}^{2} \mathrm{~T}^{\prime}\right)\right)\right]-(\mathrm{xe}-\mathrm{x}) /\left(2 \mathrm{xe}\left(\mathrm{Pi} \mathrm{T}^{\prime}\right)^{1 / 2}\right)$ ExpIntegralEi[-((xe-

$\left.\left.\left.\mathrm{x})^{2} /\left(4 \mathrm{xe}^{2} \mathrm{~T}^{\prime}\right)\right)\right]\right) / / \mathrm{N}$

val $=\{\mathrm{x}, \mathrm{T}\}^{\mathrm{T}}$

TableForm[val,TableHeadings-> \{None, $\{$ "x","T" $\}\}]$;

ListPlot[val,FrameLabel-> \{"x","T" \},Joined

-> True,PlotStyle->Red,GridLines->Automatic] 


\section{VITA}

$\begin{array}{ll}\text { Name: } & \text { Srikanth Thoram } \\ \text { Address: } & \begin{array}{l}\text { 3116 TAMU - 719 Richardson Building } \\ \text { College Station, TX 77843-3116 }\end{array} \\ \text { Email Address: } & \text { srikanth_thoram@tamu.edu } \\ \text { Education: } & \begin{array}{l}\text { B.Tech., Petroleum Engineering, Indian School of Mines } \\ \text { (Dhanbad, India), 2008. }\end{array}\end{array}$

M.S., Petroleum Engineering, Texas A\&M University

(College Station, TX), 2011. 